\title{
Simulation Support for Control Issues in the Context of Modern Diesel Air Path Systems
}

\author{
A. Albrecht, O. Grondin, J.C. Schmitt, L.M. Malbec, B. Youssef, G. Font, P. Gautier and P. Moulin \\ Institut français du pétrole, IFP, 1-4 avenue de Bois-Préau, 92852 Rueil-Malmaison Cedex - France \\ e-mail: antoine.albrech+@ifp.fr - olivier.grondin@ifp.fr - jean-christophe.schmiit@ifp.fr - lovis-marie.malbec@ifp.fr - bilal.youssef@ifp.fr - \\ gregory.font@ifp.fr - pierre.gautier@iff.fr - philippe.moulin@ifp.fr
}

Résumé - La simulation comme support pour les problématiques en contrôle dans le cadre des boucles d'air Diesel modernes - Il semble désormais évident que la boucle d'air des moteurs Diesel va devoir améliorer ses performances pour atteindre des conditions dans la chambre qui soient compatibles avec une baisse significative des émissions en sortie moteur. Cet axe important passe par l'évolution de la boucle d'air vers des systèmes plus complexes basés sur des technologies avancées comme la distribution variable ou la double suralimentation. Dans ce contexte de complexité croissante, la contrôlabilité du moteur devient un critère de premier ordre dans le choix des orientations technologiques.

Grâce à une grande flexibilité d'architecture, à la possibilité de représenter correctement les tendances et à un couplage aisé avec le contrôle moteur, la simulation $0 \mathrm{D}$ propose un support très intéressant pour aider ces développements et participer à l'identification des meilleures solutions de boucles d'air Diesel.

Ce papier présente la façon dont la simulation est devenue un outil clé pour développer le contrôle moteur sur différents types de boucle d'air avant même d'avoir un moteur disponible au banc afin d'anticiper les points durs et de commencer à évaluer la contrôlabilité des différentes technologies dès les premières étapes du processus de développement moteur.

\footnotetext{
Abstract - Simulation Support for Control Issues in the Context of Modern Diesel Air Path Systems - It is now obvious that the air path system will have to increase its performance to manage the in-cylinder conditions required by the combustion process if significant raw emission reduction is expected in Diesel engine applications. This crucial issue means air path evolutions with complex systems including advanced technologies such as Variable Valve Actuation (VVA) or two-stage turbocharging, and engine control capability improvement to optimise accurately the engine behaviour under transient conditions. At this stage of complexity, the engine controllability becomes a first-order factor to be taken into account in the technological orientations.

Thanks to a high versatility of engine architecture, good physical trend capabilities and easy coupling with engine control, $O D$ simulation offers a very interesting support to help such investigations and discriminate the best Diesel air path system solutions.

This paper describes how simulation is becoming a key tool to develop the control for various Diesel air path systems before having the corresponding experimental bench available, in order to anticipate the hard issues and begin to assess the controllability of each air path technology at the early stages of the engine development process.
} 


\section{ABBREVIATIONS}

$\begin{array}{ll}\text { AFR } & \text { Air Fuel equivalence Ratio } \\ \text { BGR } & \text { Burned Gas Ratio } \\ \text { CA } & \text { Crank Angle } \\ \text { CI } & \text { Compressed Ignition } \\ \text { CO } & \text { Carbon Oxide } \\ \text { CPU } & \text { Central Processing Unit } \\ \text { DPF } & \text { Diesel Particle Filter } \\ \text { ECP } & \text { Exhaust Counter-Pressure } \\ \text { ECU } & \text { Engine Control Unit } \\ \text { EGR } & \text { Exhaust Gas Recirculation } \\ \text { HCCI } & \text { Homogeneous Charge Compressed Ignition } \\ \text { HP } & \text { High-Pressure } \\ \text { IMEP } & \text { Indicated Mean Effective Pressure } \\ \text { LP } & \text { Low-Pressure } \\ \text { LTC } & \text { Low Temperature Combustion } \\ N & \text { Turbocharger speed } \\ N d & \text { Target turbocharger speed } \\ \text { Ne } & \text { Engine Speed } \\ \text { NEDC } & \text { New European Driving Cycle } \\ \text { NOx } & \text { Nitric Oxides } \\ P & \text { Pressure } \\ P R & \text { Pressure Ratio } \\ Q & \text { Mass Flow } \\ T & \text { Temperature } \\ \text { TS } & \text { Two-Stage } \\ \text { UHC } & \text { Unburned Hydrocarbon } \\ \text { VVA } & \text { Variable Valve Actuation } \\ \text { VGT } & \text { Variable Geometry Turbine } \\ W G & \text { Waste Gate } \\ \text { meas } & \text { measured } \\ \text { sp } & \text { set point } \\ \text { sural } & \text { supercharging } \\ \text { t } & \text { turbine } \\ & \end{array}$

\section{INTRODUCTION}

The usage of high levels of burned gas for Diesel combustion is an indisputable way to reduce the NOx emissions at low and part loads thanks to Low Temperature Combustion (LTC). If this increase in Exhaust Gas Recirculation (EGR) has a high benefit for emission, it has to deal with various drawbacks, for example:

- the fuel/air equivalence ratio increase, which leads to high smoke emission,

- the intake temperature increase, which can impact the combustion strategy,

- the transient response time due to the EGR circuit, which can lead to losing during transients all the benefits earned under steady-state conditions.
A major issue in the development of these future Diesel engines lies in the architecture and the control of the air intake. To face these issues, the future Diesel engines will be equipped with complex air paths. A two-stage turbocharger may help to reduce the fuel/air equivalence ratio, variable actuation allows the reduction of the response time to high EGR demand, etc. In this context, the associated control laws have to be modified: the conventional strategies based on steady-state maps and proportional integral controllers have to be improved in order to address the new challenges.

Moreover, this corresponds to an increasing number of technological options to be investigated and the engine control becomes a critical issue which has to be taken into account for the air path design choice. In this context, simulation is a versatile support with ideal characteristics to be used as a virtual bench for control development under certain conditions.

This paper presents the way simulation is used to support the air path control development for the typical Diesel air and EGR systems investigated for future Diesel engine applications when the engine bench is not yet available. In the first section, the ways in which 0D simulation is a powerful tool which deserves to be more exploited for engine development projects is introduced. Then, the paper presents, using on-going project examples, the way a reference engine simulator can be set up and adapted to be used for various air path architecture issues currently investigated for Diesel engines: to enhance the current system performance, to manage the alternative EGR systems and to ensure air boost high performances.

\section{TOWARDS THE NUMERICAL POWERTRAIN}

\subsection{The Simulation-Based Development Process}

Thanks to a coherent model development and simulation platform, 0D simulation, when it is based on a physical modelling approach, represents a strong key point to reduce the time and cost of the powertrain development process (Fig. 1). If the development of the simulator increases the time and the cost a little at the first stage of the project, its usage quickly becomes a strong tool to support technological decisions and to reduce experimental tests. Finally, this approach allows one to save time and money. Moreover, the simulation approach is a very efficient way to understand the system better during and after the development process and allows an increase in the global knowledge. Compared with a conventional development process only based on experimental support, using simulation throughout the development process has numerous advantages:

- before the experimental phase: it is useful to assess the new concept performances, to compare the different technological solutions and to anticipate some investigations thanks to a baseline simulator, 


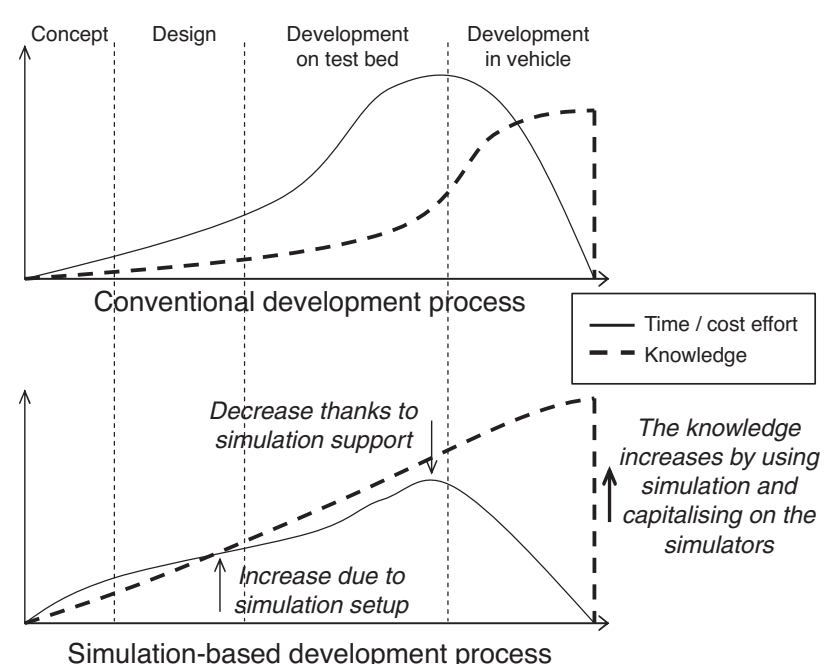

Figure 1

Conventional and simulation-based development process comparison.

- during the experimental phase: it allows one to access non-measurable information, to reduce the number and the duration of the experimental tests being used as a virtual bench for control and pre-calibration, to investigate architecture and engine tuning issues and to anticipate the corresponding results in the target vehicle. Moreover, simulation is a very convenient way to perform tests difficult to achieve experimentally such as sensor or component failure and non-standard conditions such as altitude conditions,
- after the experimental phase: simulation is a very efficient way to capitalise on the knowledge about the system and to be able to perform additional tests if necessary.

\subsection{The Air Path Control-Oriented Simulator}

Unfortunately, it is unrealistic at this time to expect that a single simulator will match the specific requirements of each of the applications that the simulation can be used for in the engine development process. To avoid the disappointment of the universal model myth, these application expectations have to be accurately defined in order to set up or adapt the relevant simulation with a coherent model level, especially when few experimental data or short time is available. That is why the methodology definition for building the simulator is a very important phase to ensure a good match between the model level, the available data and the application goals.

It is a fact that the simulation-based approach is especially adapted for control design because simulation is well adapted to fulfill the control requirements [1]: dynamic trends, closed-loop operating conditions, support versatility (leakage, dispersion, etc.), fast CPU performance, etc. The following parts describe how the simulation support can be set up and adapted for the different air path architectures and control issues with reduced experimental data.

It is possible to adapt the $0 \mathrm{D}$ models used in the simulator to fit with the evolution of the control expectations such as real-time performance, for example. The way the simulator is developed at IFP in various specific versions for the specific control development stage is represented in Figure 2.

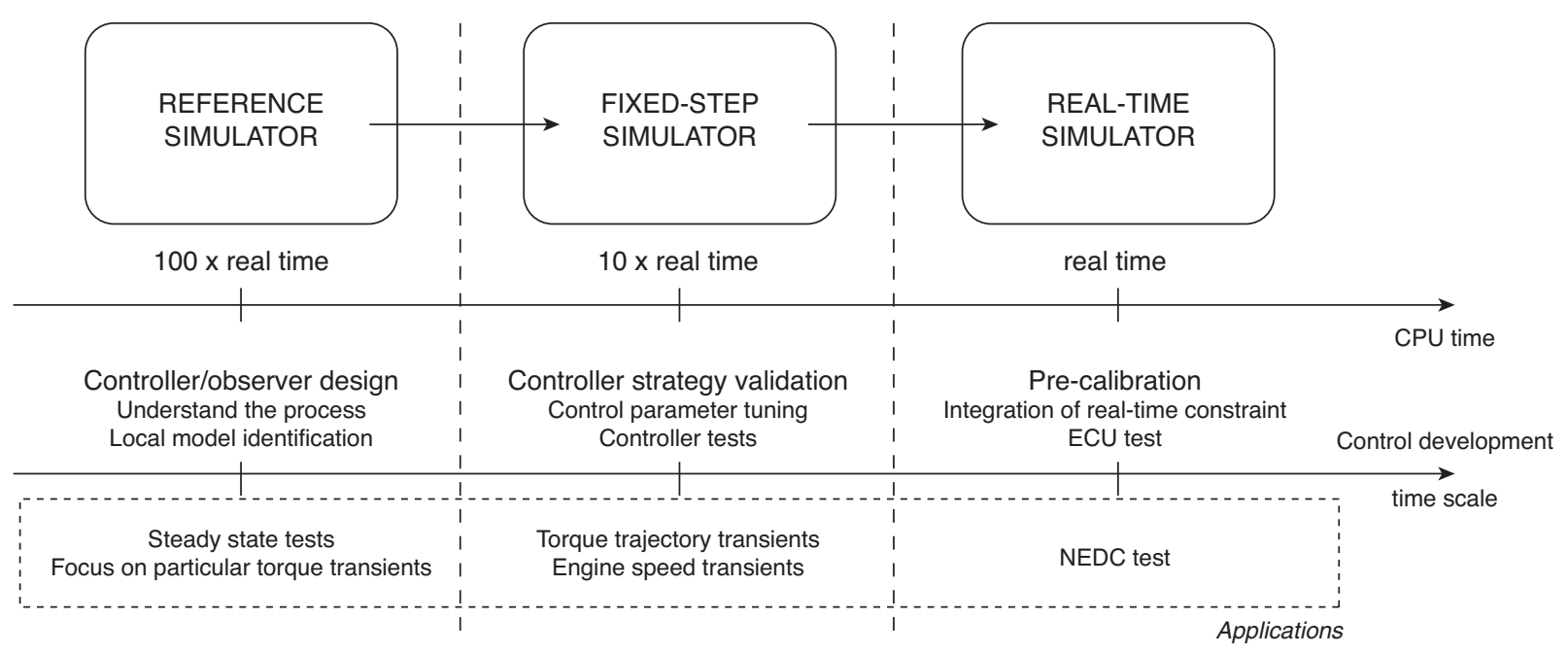

Figure 2

Schematic diagram of the engine simulation-based control design methodology. 
To be relevant for the air path control design applications, the simulation is not expected to reach very accurate behaviour compared with a real engine. At first, the control design is focused on the air path, which means that the combustion model just needs to have good performances for boundary conditions for intake and exhaust gas exchanges and to give reasonable results for the engine torque. In such a context, high representative capability is not expected for the combustion process (auto-ignition delay, maximum pressure, CAx, noise, pollutant), as it is the case for complete engine control development [2]. That is why the combustion model tuning does not have to be very accurate and can only be based on a combustion from an engine as similar as possible. Another important point is that the simulator will be coupled with the control and run in a closed-loop configuration. It means that the actuator modelling is not of first order for this application. The goal is to have good dimensions for the engine air path (pipe lengths and diameters, throttle and valve sections, heat exchanger volumes) to have a correct dynamics response of the system, but an accurate estimation of the air path actuator positions is not expected. This is the reason why it is a very relevant framework to take benefit from the OD simulation physical models.

Each of the following three sections presents an air path control design application example focused on a different air path system, using simulation intensively as development support.

\section{SINGLE-STAGE TURBO WITH HP EGR LOOP: TO ENHANCE THE CURRENT SYSTEM PERFORMANCES}

This section describes how an engine simulation tool has been used to improve a model-based control strategy for a variable geometry turbocharger.

\subsection{Context}

Figure 3 shows the experimental setup used in this study.

The turbine is a Variable Geometry Turbine (VGT): a set of movable vanes in the turbine housing modifies the mass flow rate and thus the energy available for the turbine. The engine is also equipped with a high-pressure injection system, an Exhaust Gas Recirculation (EGR) vane and intake throttle. The detailed engine description is available in [3]. Fresh air enters the system through the air filter and then it is compressed by the compressor. To increase air density, the temperature gained through the compressor is reduced by the heat exchanger. The mixture of the intake air with injected fuel into cylinders produces engine torque. The exhaust gases store a lot of energy in terms of heat (enthalpy). This energy goes through the after-treatment system and is lost for the torque production. The function of the turbocharger system is

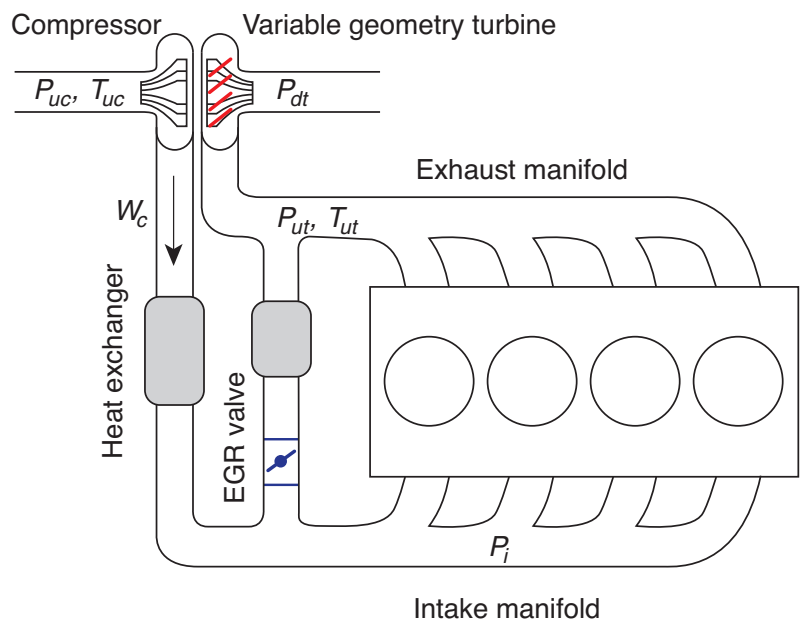

Figure 3

VGT engine schematic diagram.

to transfer part of this energy to the intake gases and thus increase the overall engine efficiency. The turbine uses this stored energy to produce mechanical torque which drives the compressor via a shaft. The intake pressure is thus increased, which allows running the engine on a wider operating range than a naturally aspirated engine.

In parallel with the turbocharger, part of the exhaust gas flow is recirculated to the intake via the EGR circuit. There exists an interaction between these two systems since an increase in the EGR gas mass flow results in two effects: a decrease in the air mass flow through the compressor and a decrease in the energy available for the turbine.

\subsection{Specific VGT Control Issues}

The objective of the air path management structure is to control the quantity and the composition of the gas masses entering the engine. For this purpose, different choices can be made in terms of control variables. Generally, the structure used to control the air system consists of two parallel linear controllers with gain scheduling and feed-forward values given by maps. A first controller deals with the intake pressure using the actuator of the turbocharger system (VGT), while the second one deals with the EGR flow via the EGR valve.

Compared with a conventional combustion mode, the Low Temperature Combustion (LTC) mode requires both high supercharging pressure and high EGR rate, thus creating a high interaction between the two controllers described. The solution retained by the IFP for controlling this kind of Diesel engine is to underlie the control laws with physical 


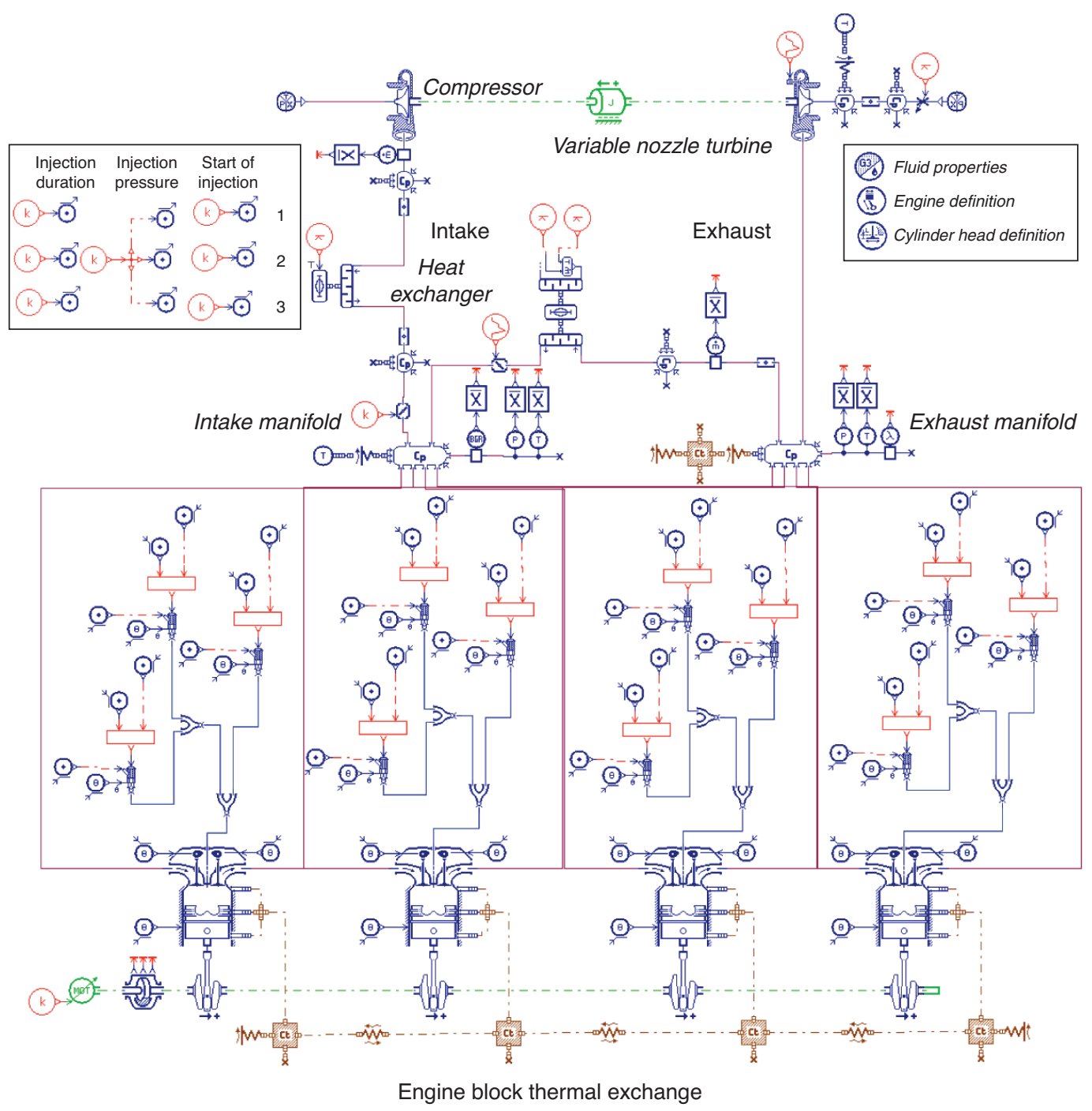

Figure 4

HCCI engine simulator diagram.

models of the EGR loop and of the turbocharging system. This approach is named model-based control.

\subsection{Modelling Aspects}

In this study, the engine simulator is based on the simulator developed for the control design for the HCCI Diesel engine application presented in Figure 3 [2]. The simulation tool is the AMESim modelling environment edited by LMS IMAGINE.Lab with the IFP-ENGINE library. This engine simulator diagram is presented in Figure 4.

Before being used for engine control design, the engine simulator has to be calibrated to behave as closely as possible to the real engine. If experimental results are already available, the comparison with test bed results is the best way to achieve and validate this calibration. To be complete, this process is performed for a large amount of operating set points, under steady-state and transient conditions, with an open-loop and a closed-loop control. According to the experimental acquisitions, mean but also instantaneous engine characteristic values from the simulator and test bed may be compared. Finally, the goal is to obtain satisfactory results from the engine with the same parameter set for all the validation tests.

Figure 5 presents some results obtained with a simulator under steady-state conditions in a wide range of operating set points. 86 set points have been computed from low load to full load for 5 engine speeds: 1500, 2000, 2750, 3000 and $4000 \mathrm{rpm}$. The comparison with the bench data shows 

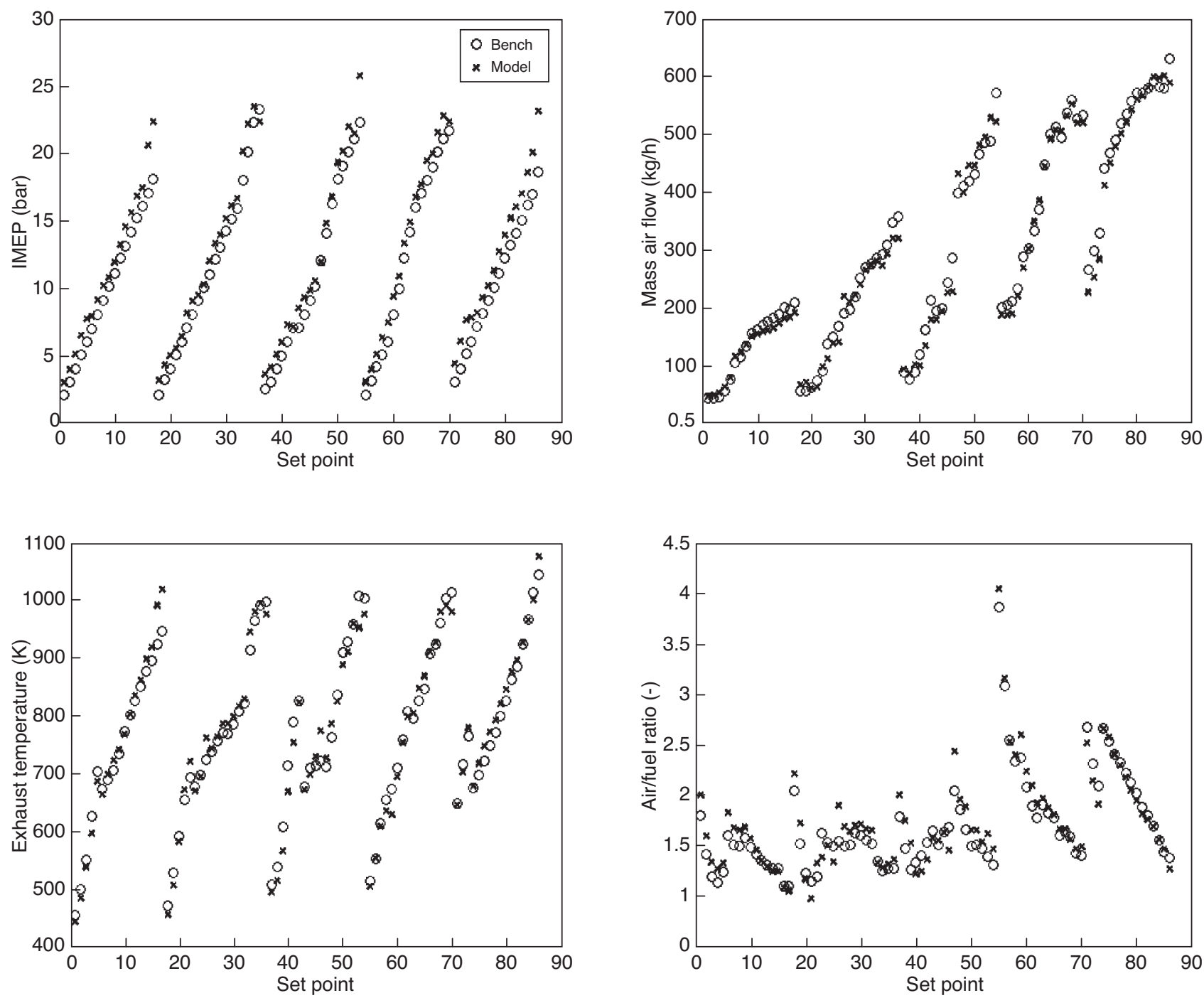

Figure 5

Model/bench result comparison on load and speed steady-state set points.

the good agreement on the IMEP, mass air flow, exhaust temperature and Air/Fuel equivalence Ratio (AFR) as examples. This validation assesses the load/speed area that can be investigated using the engine simulator.

Since engine control deals with transient issues, the engine simulators have to be tested under transient conditions. Figure 6 to Figure 10 present some examples of the reference engine simulator validation under transient conditions for a torque trajectory at $2000 \mathrm{rpm}$. These results were performed under open-loop conditions, which is a quite severe test for the model because any small deviation to a real engine test may be emphasised by the absence of engine control. According to these assumptions, the engine simulator shows a good accuracy for the engine dynamic behaviour.

\subsection{Simulation-Based VGT Control Study}

The model-based control laws studied in this section are described in [4]. A control strategy based on a physical model of the turbocharger system is proposed. The control law is designed by exploiting a new structure of the system obtained after an appropriate variable change. The intake pressure set point is transformed into a turbocharger speed set point. By a simple technique of back-stepping, the system is forced to follow its set point with an exponential decay. An integral term can be added to the control law in order to compensate for modelling error. The final turbocharger control structure depends on three parameters: the time constant of the set point filter, the decay constant and the integral gain. 


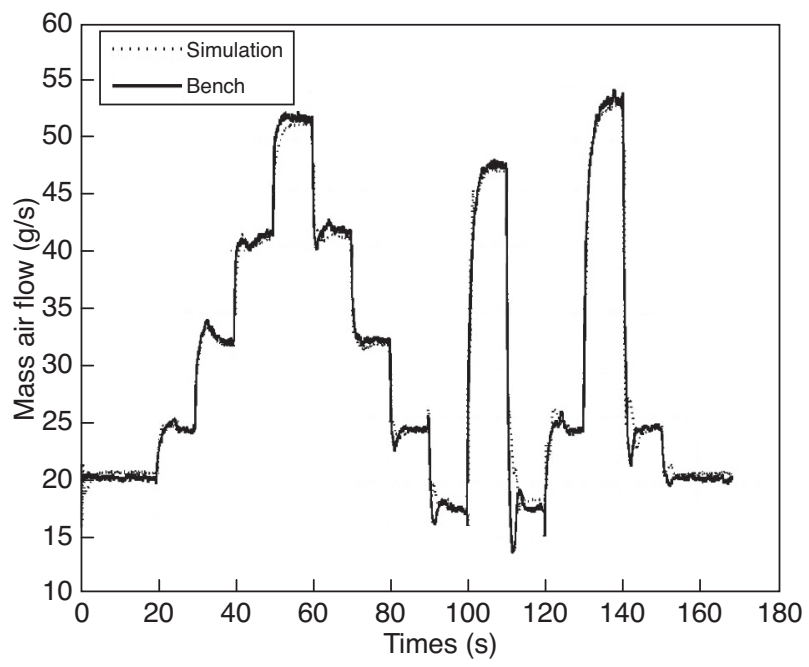

Figure 6

Model/bench mass air flow comparison for a load variation at $2000 \mathrm{rpm}$.

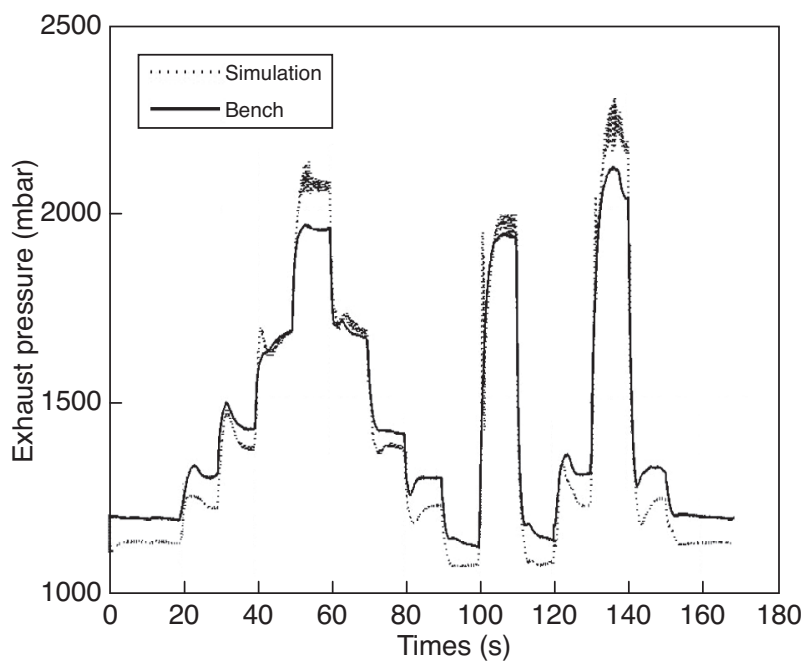

Figure 8

Model/bench exhaust pressure comparison for a load variation at $2000 \mathrm{rpm}$.

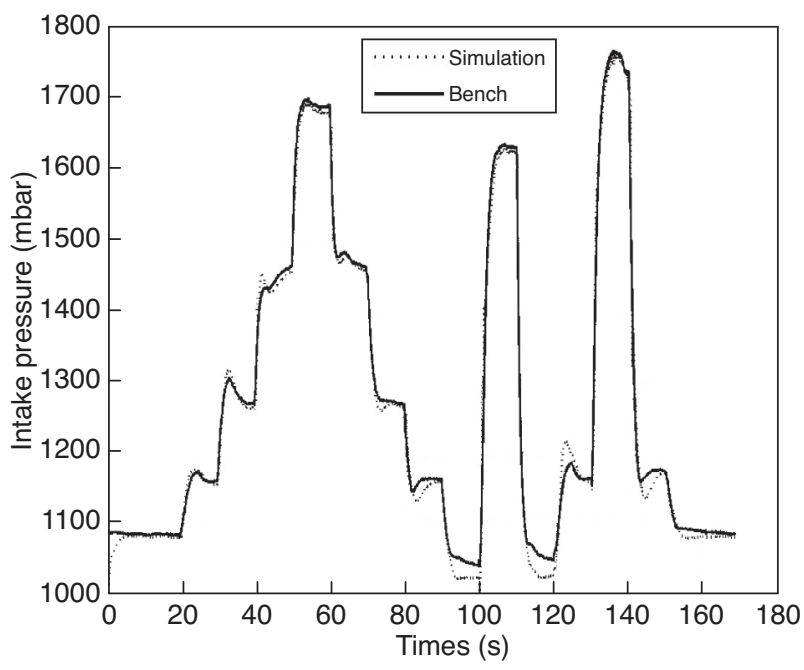

Figure 7

Model/bench intake pressure comparison for a load variation at $2000 \mathrm{rpm}$.

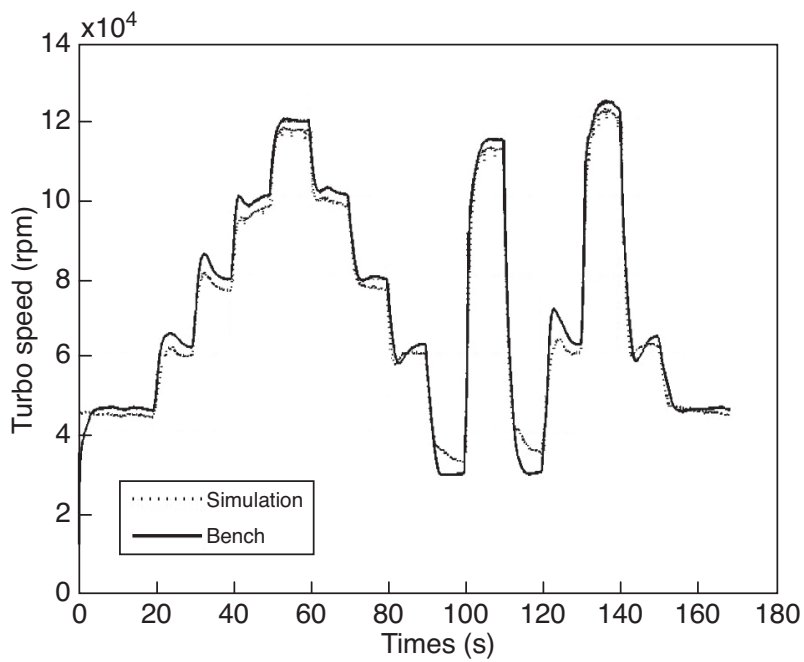

Figure 9

Model/bench turbo speed comparison for a load variation at $2000 \mathrm{rpm}$.
The first two parameters act on the system dynamic, while the last one acts on the steady-state error.

A coupled simulation structure was used to connect the engine simulator and the global control scheme. The engine simulator uses the AMESim software, which interfaces with Matlab/Simulink for the control purpose. This structure is very close to that applied to the real system with the engine, the engine sensors, the engine command unit and the engine actuators coupled together (Fig. 11).

The tuning of the control law remains simple. The model is parameterised using physical constants or manufacturer maps which are available. Thanks to the model-based control structure, only the above three parameters need to be calibrated, which represents a great gain compared with a more conventional control structure.

Figure 12 shows the response of the controlled boost pressure corresponding to an arbitrary torque trajectory at a constant engine speed (1500 rpm). The reference pressure is the target corresponding to the torque demand. The boost pressure is simulated by the engine simulator.

The boost pressure demand is translated by the boost control into a reference turbocharger speed $(N d)$. The current 


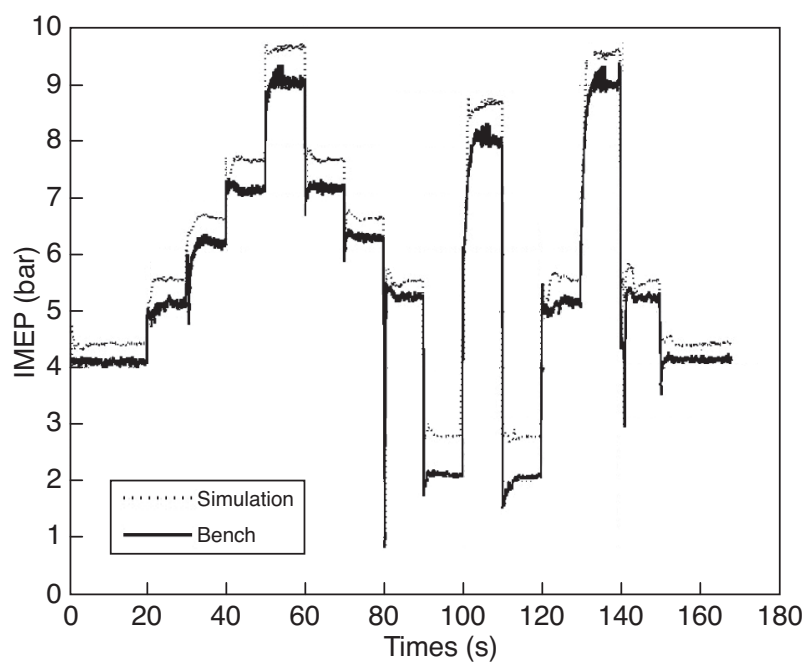

Figure 10

IMEP comparison for a load variation at $2000 \mathrm{rpm}$.

turbocharger speed $(N)$ is calculated too. The response of the system in terms of turbocharger speed is given by Figure 13.

The VGT command is the output of the controller, used by the engine simulator to compute the position of the set of movable vanes in the turbine housing. The evolution of this command is presented in Figure 14.

The simulation results demonstrate the performance of the proposed structure. The VGT actuator responds quickly, the response time is close to $2 \mathrm{~s}$ and there is no steady-state error.

At this stage, the concept of the model-based boost pressure controller has been validated by the simulation tool. The proposed turbocharger control strategy can now be tested on a four-cylinder engine test bench. The performances in this case are similar to those obtained in the simulation (Fig. 15).

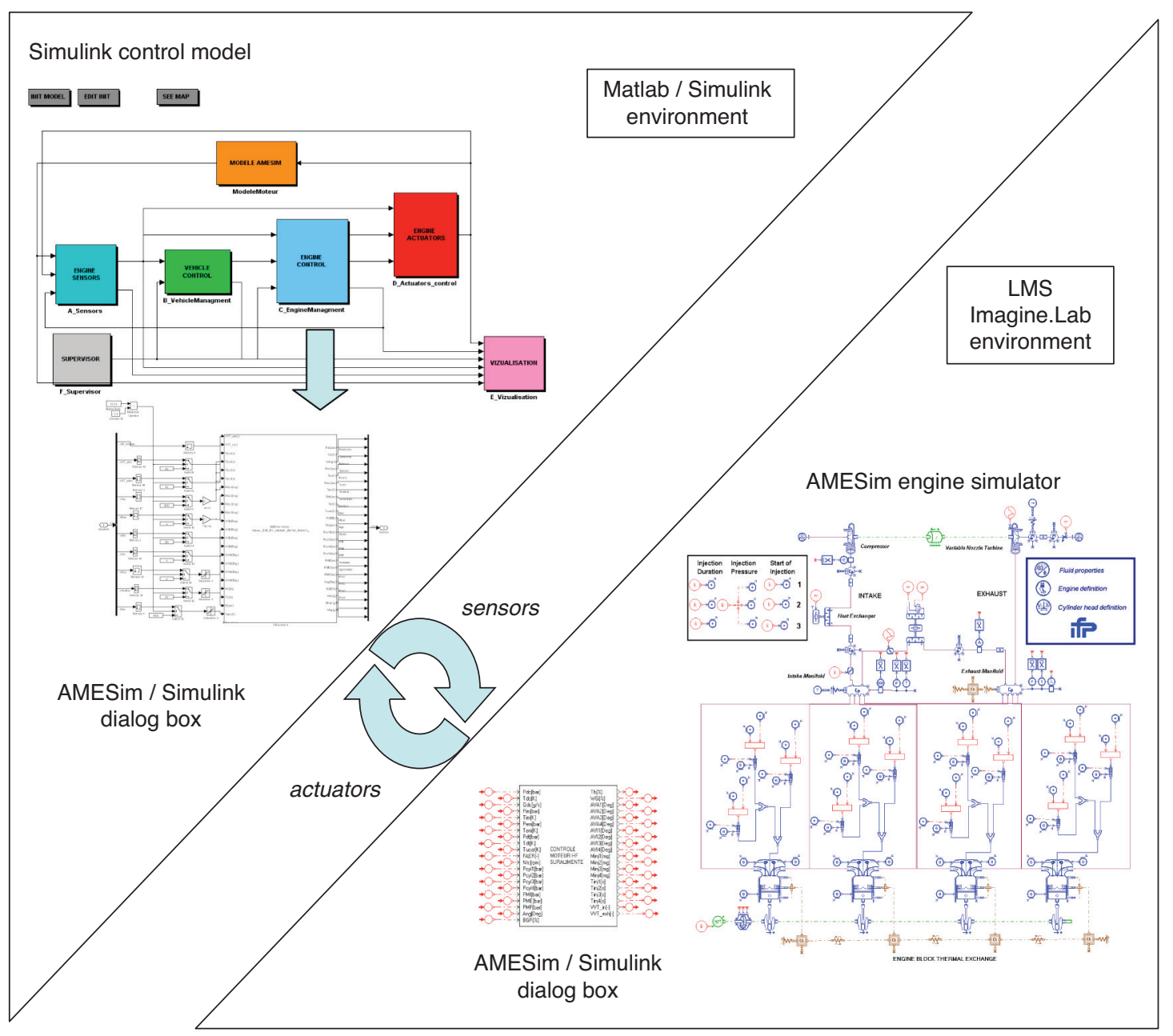

Figure 11

AMESim / Simulink co-simulation platform. 


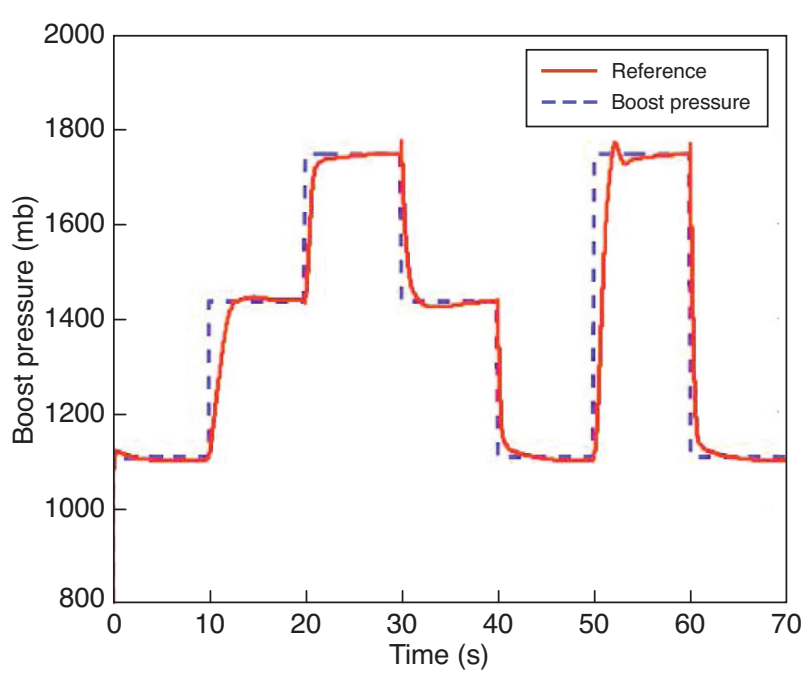

Figure 12

Response of the controlled boost pressure in the engine simulator.

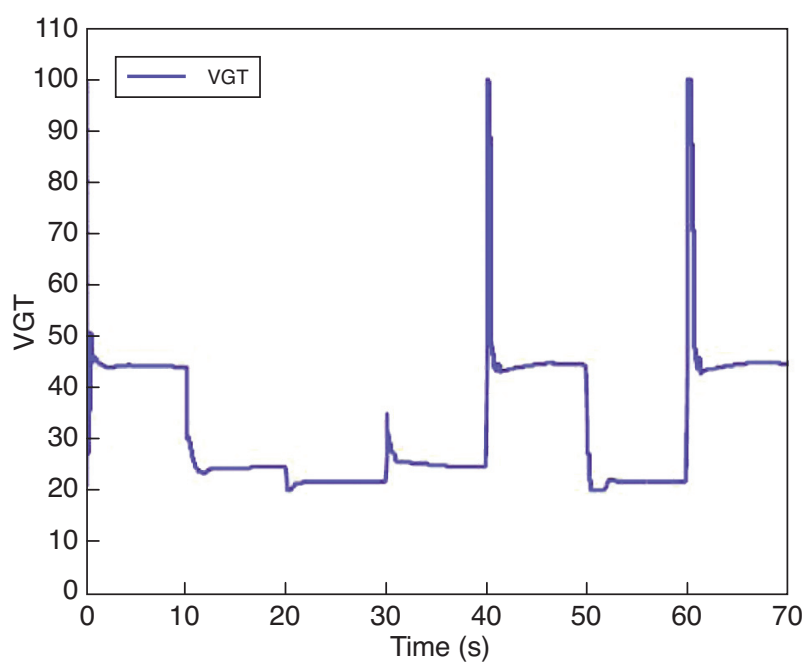

Figure 14

VGT trajectory to track the boost pressure target with the simulator.

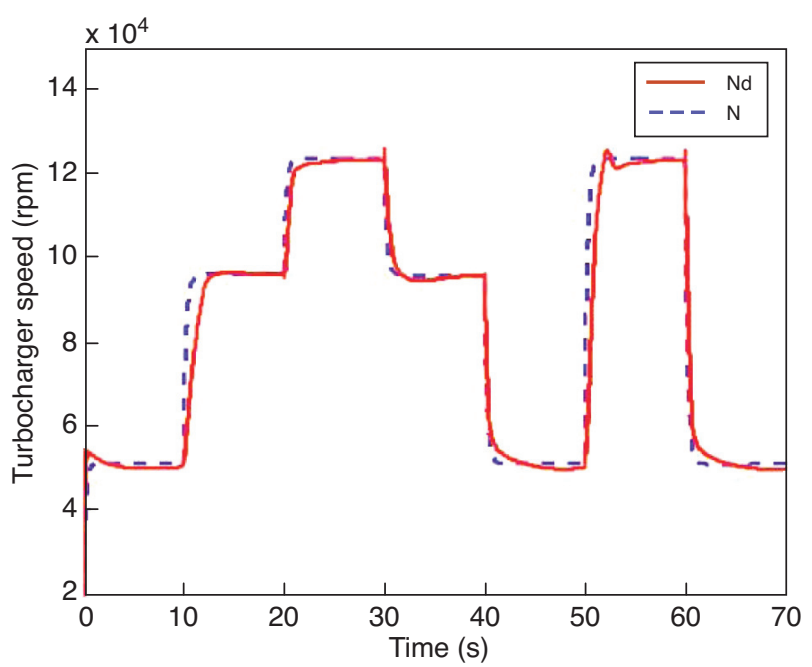

Figure 13

Response of the turbocharger speed $(N)$ in the engine simulator ( $N d$ is the reference turbocharger speed from the control).
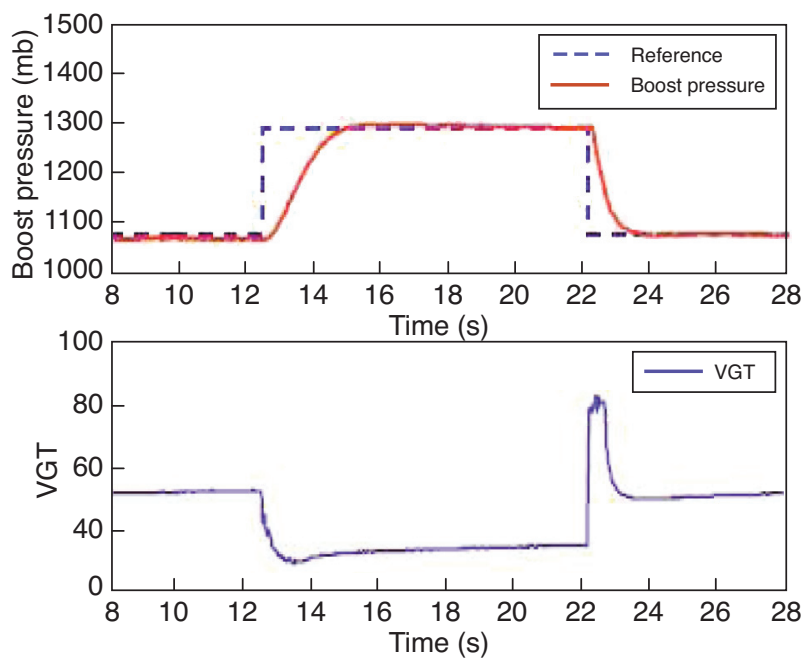

Figure 15

Response of the controlled boost pressure: validation example at the engine test bench.

\section{HP/LP EGR LOOPS AND VVA: TO MANAGE THE ALTERNATIVE EGR SYSTEMS}

This section deals with simulation use to support the control design for EGR system management.

\subsection{Context}

The new CI combustion modes based on high EGR levels have demonstrated a great potential to lower the raw engine emissions, especially the nitric oxide (NOx) ones. The NOx emissions are strongly linked with flame temperature [5] and EGR is a very efficient method to lower the production of NOx during the combustion process. The high EGR rate used in LTC increases the heat capacity of the in-cylinder mixture, resulting in lower flame temperature [6]. Moreover, due to high dilution the combustion process starts later (in the expansion stroke) and thus, lower peak temperatures are reached. As a consequence, very low NOx emission levels can be achieved without the need for expensive NOx aftertreatment devices. 
The need for a high rate of EGR involves a modification of the conventional Diesel engine architecture. The exhaust gas recirculation can be achieved though an internal or external way. For the practical application of external EGR, three main configurations are possible:

\subsubsection{The High-Pressure (HP) EGR}

The burned gases are taken from the exhaust manifold upstream of the turbine inlet and reintroduced into the intake manifold. This system includes a valve and an EGR cooler. In this configuration the exhaust gases are unfiltered and this can lead to EGR cooler fouling, resulting in a drop in cooler efficiency. This system tends to reduce the turbine flow since not all exhaust gases pass through the turbine. This decreases the turbine efficiency. However, the HP EGR loop has a faster settling time than that of the LP EGR circuit.

\subsubsection{The Low-Pressure (LP) EGR}

In this configuration, the burned gases are taken downstream of the particulate filter (DPF). The LP circuit includes an EGR valve, an EGR cooler, and usually an exhaust throttle is necessary to create sufficient pressure drop in the EGR system to ensure the EGR flow. The burned gases are reintroduced upstream of the compressor. The EGR gases are filtered and this limits the impact on the EGR cooler. With the LP EGR system all exhaust gases flow though the turbine; this allows optimisation of the supercharging system. However, the settling time of the low-pressure loop is longer than that of the high-pressure loop. This aspect must be carefully taken into account in the control system.

\subsubsection{The Combination of HP and LP EGR Systems}

In modern Diesel engines, the two previous EGR configurations can be combined to take advantage of both systems. The HP system can be used when short EGR settling time is needed, while the LP system can be applied at part load to extend the LTC region without affecting the supercharging performances. By combining these two systems, it seems that one possible solution is to use the high-pressure system during fast and large transients and to recirculate EGR from the low-pressure circuit when the EGR is close to its set point.

The internal EGR can be controlled by means of new valve systems such as Variable Valve Actuation (VVA). This system is generally combined with external EGR systems. The VVA simulation is reported in Section 3.5.

In the first part of this section we consider the engine architecture depicted in Figure 16. The engine is a four-cylinder direct injection with a dual combustion mode combining Compression Ignition (CI) operations from part to high loads with Low Temperature Combustion (LTC). The combustion concept has been presented in [7]. The fuel path system includes a Diesel common-rail injection system with solenoid injectors. The air path system contains three different parts: the high-pressure EGR system, the low-pressure EGR system and the air system. The EGR system is controlled by a valve located downstream of the EGR cooler. This latter can be bypassed during cold start operation to warm the engine faster. When the engine is warm the cooled EGR gases are reintroduced. Then, hot EGR is applied. The LP EGR flow is controlled with the LP EGR valve and the exhaust throttle. A Variable Geometry Turbocharger (VGT) is fitted to control the boost pressure control. An intake throttle, located downstream of the air cooler, can be used in transient operations to slow down the air flow (in HP EGR operation only).

\subsection{Control Challenges for External EGR Systems}

On one hand, the air path architecture is modified due to the need for a higher burned gas ratio; this necessarily increases the system complexity, as shown in Figure 16 (with the introduction of a greater degree of freedom and more cross-coupling between variables). On the other hand, the LTC is very sensitive according to air path error and the maximum benefit of LTC is obtained when the system operates close to its stability limit. As a consequence of these two assertions, the air path control becomes a real challenge. Because of the high complexity of the dual external EGR system (HP and LP) combined with a variable geometry turbocharger, the standard control approaches based on linear controllers are not suitable. The control issues related to the HP EGR combined with the VGT have been reported in [9]. The main control issues with a dual-loop EGR system are listed below:

\subsubsection{Intake Manifold Gas Composition Estimation}

The intake condition can be represented by the burned gas ratioaction of burned gas contained in the intake manifold. The BGR is one of the key variables in LTC or HCCI combustion. However, there is no available sensor for the production engine and static estimation is not sufficient for transient control. For that reason, the BGR must be estimated. The BGR is a consequence of the air flow and the HP and LP EGR flows. The air flow is measured but the main difficulty is estimating the two EGR flows in any possible combination:

- a single HP EGR flow,

- a single LP EGR flow or,

- simultaneous HP and LP EGR flows.

Some work has been reported on the intake composition estimation in HP EGR loop configuration (open-loop observer [10] and closed-loop observer [8]). The basis of these two estimators can be transposed to the LP EGR system with the same configuration in terms of sensors. However, the simultaneous estimation of the two flows is an ongoing work; some preliminary results are presented in [6] and [11]. 


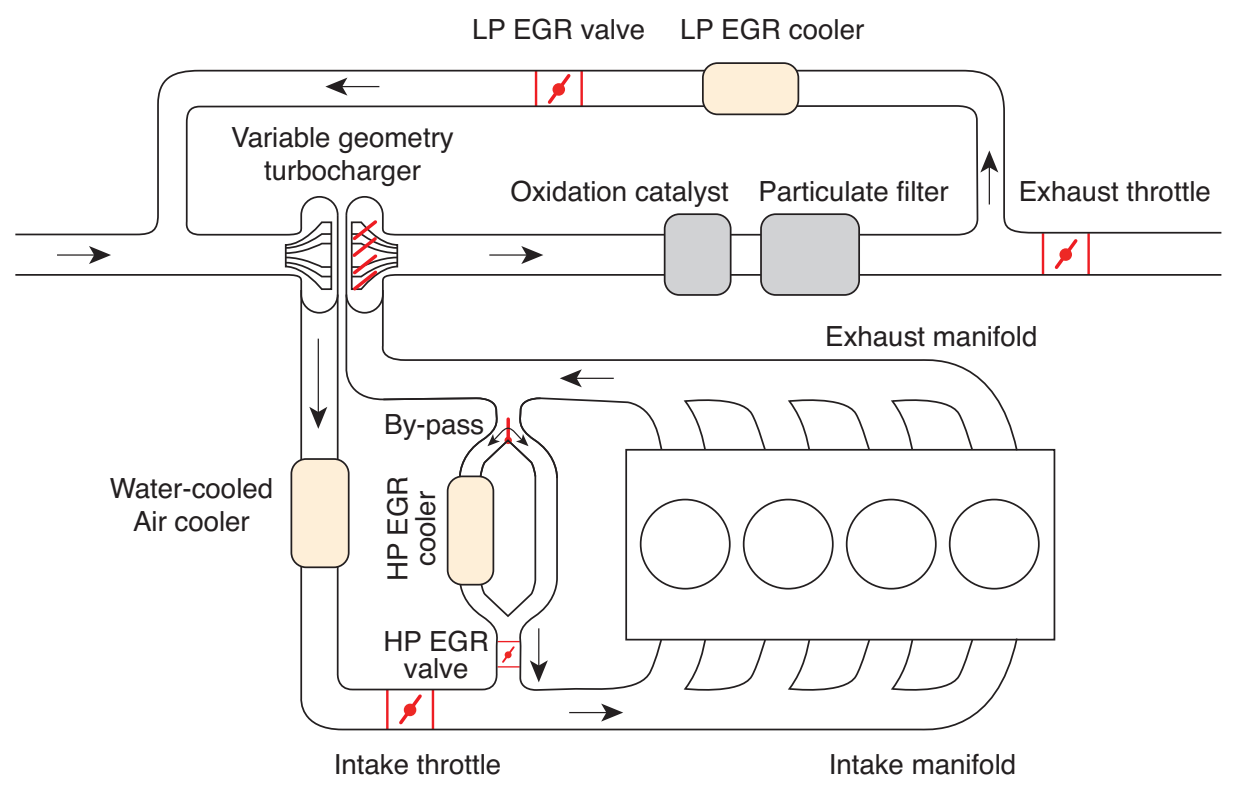

Figure 16

Dual-mode (LTC-CI) engine fitted with HP and LP EGR circuits.

\subsubsection{Air and EGR Flow Control}

The main control problem comes from the coupling between the air loop and the EGR loops. This task has been addressed by many authors in the past year $[8,9]$ ) for the HP EGR system coupled with a VGT (see also Sect. 2). In the case of the dual EGR system, the control problem is more complex due to the number of the control inputs: the HP EGR flow is controlled by the position of the HP valve and the intake throttle, the LP EGR flow is controlled by the LP valve and the exhaust throttle, and the air flow is modified by moving the VGT position. The engine control is in charge of managing the intake manifold pressure and composition with 5 actuators. On one hand, the use of HP or LP EGR modifies the intake to exhaust pressure balance. The VGT position must be adapted accordingly. On the other hand, the VGT position changes the exhaust pressure and thus the HP EGR flow that depend on the EGR valve pressure ratio. In LP EGR mode, the use of exhaust throttling tends to vary the turbine pressure ratio, which is a key variable for the turbocharger control. For all these reasons, the standard linear controller cannot be implemented without a large calibration effort. In this context, the model-based EGR and turbocharger control are preferred to deal with these issues [4].

\subsubsection{HP and LP Flow Supervision}

Since the control system is able to estimate and to control both EGR flows, the supervision task must be addressed. The supervision strategies depend on the static operating regions where HP or LP EGR must be applied and also on the transient conditions where switching between these two modes is possible.

\subsection{Engine Simulator with HP and LP EGR System Combination}

The engine simulator equipped with HP and LP EGR systems was derived from the engine simulator presented in Section 2. Therefore, the air path and the HP EGR circuit are assumed to be already validated and the simulator setup is focused on the additional low-pressure loop.

\subsubsection{EGR Circuit Modelling Based on Bond Graph}

The engine OD model is based on Bond-Graph theory [12], in which the basic elements are classified into two categories:

- the resistive elements (R): they resolve mass and energy flow rates from pressure, temperature and gas composition at their bounds. The charge losses of such elements must be calibrated through their effective section and their roughness (flow parameter),

- the capacitive elements (C): they resolve pressure, temperature and gas composition from mass and energy flow rates and mass fractions at their bounds. The volume and heat exchanges of such elements must be calibrated. 


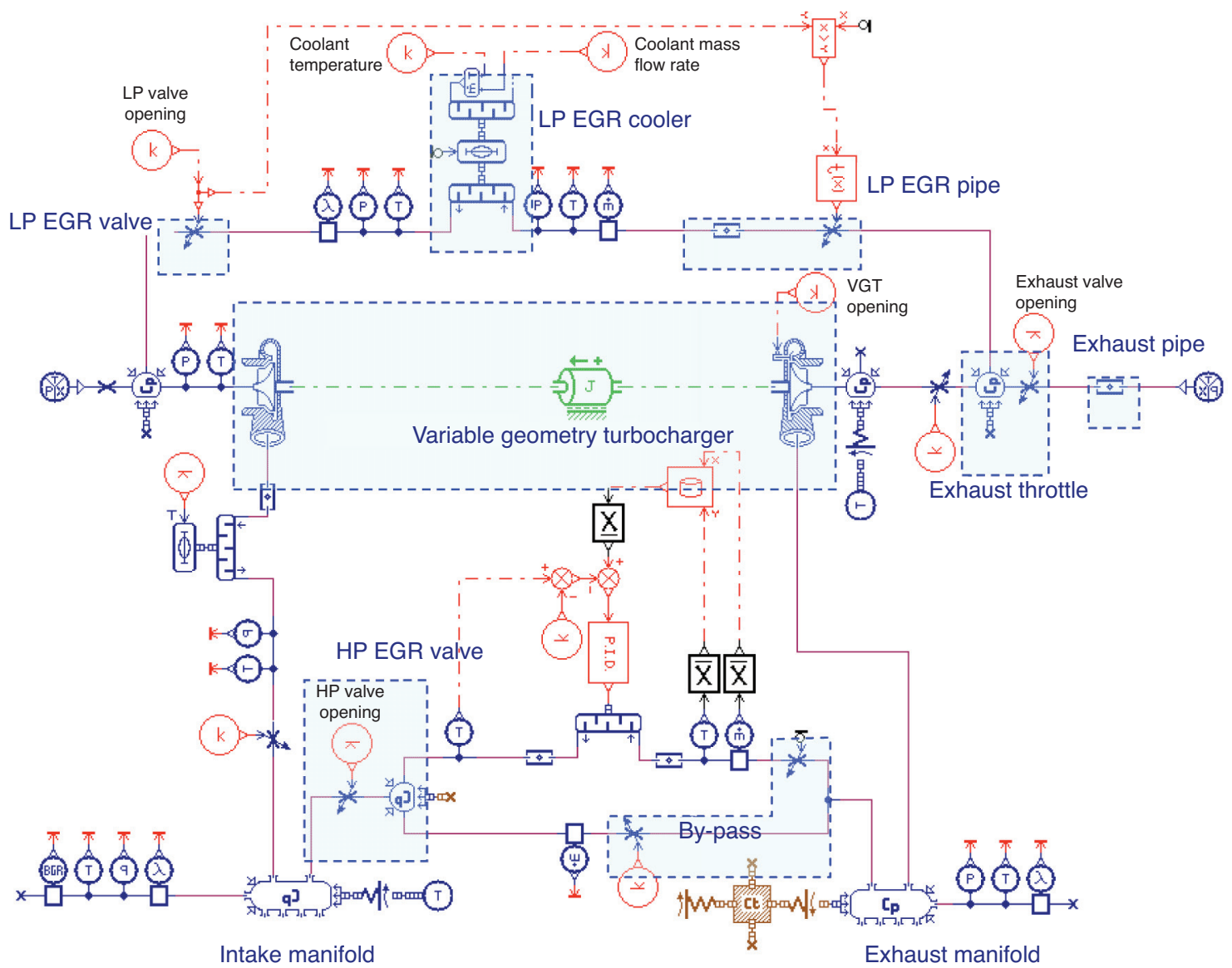

Figure 17

Focus on the air path simulator diagram including a VGT, HP EGR circuit and LP EGR circuit.

The engine model is an alternation of capacitive and resistive elements (Fig. 17).

This LP EGR loop is composed of five elements which need to be calibrated:

- the LP EGR valve (R),

- the LP EGR heat exchanger $(\mathrm{R}+\mathrm{C})$,

- the LP EGR pipe $(\mathrm{R}+\mathrm{C})$,

- the exhaust throttle $(\mathrm{R}+\mathrm{C})$,

- the exhaust pipe $(\mathrm{R}+\mathrm{C})$.

In the engine simulator, the volumes of capacitive elements are close to the measured value in the real engine. There are no heat exchanges except in the LP EGR heat exchanger. The difficulty lies in the calibration of the resistive elements because the LP EGR circuit deals with very low-pressure drops. These elements are modelled using the well-known Barré Saint-Venant equation. For the models of the LP EGR valve, the LP EGR heat exchanger, the LP EGR pipe and the exhaust throttle, the flow parameter has been set to a constant and the friction loss calibration is carried out through the value of the effective section. For the LP EGR valve and the exhaust throttle, this section varies and is piloted, as is the case in the real engine. In this study, the test bench results allow access to upstream and downstream conditions, mass flow rates, and valve and throttle set points for many operating points, which enable effective section computation by inversion of the Barré SaintVenant equation. These four elements (LP EGR valve, LP EGR heat exchanger, LP EGR pipe and exhaust throttle) are calibrated with this methodology.

Because of the lack of experimental measurements concerning the exhaust pipe downstream pressure, this methodology cannot be used for its calibration. Nevertheless, the pressure drop of the test bench exhaust line is known: $210 \mathrm{mbar}$ for $600 \mathrm{~kg} / \mathrm{h}$ at $600^{\circ} \mathrm{C}$. The exhaust pipe effective section is thus calibrated to obtain the same pressure drop. 

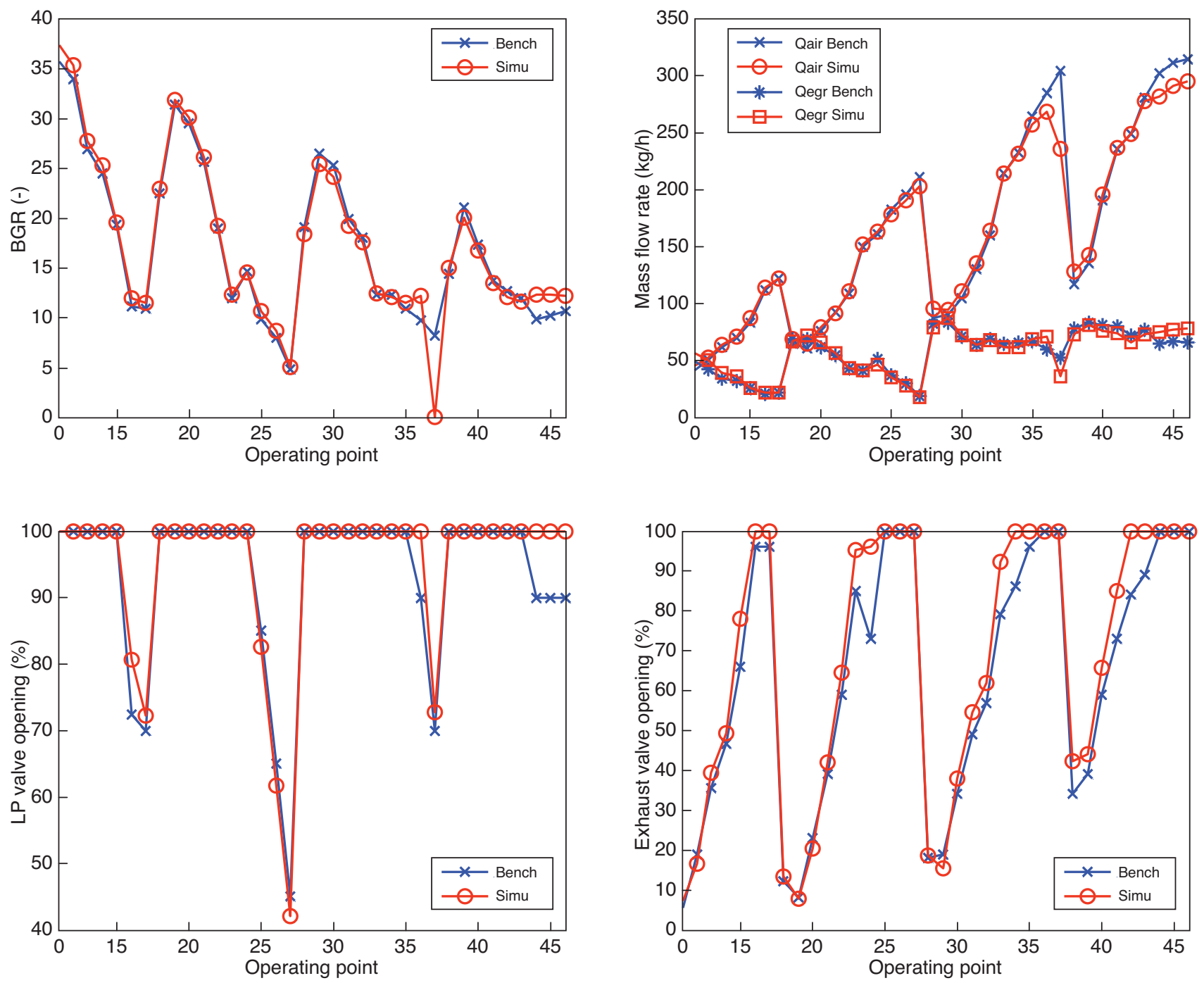

Figure 18

Comparison between simulation and test bench steady-state results.

\subsubsection{LP EGR Circuit Steady-State Validation}

The LP EGR loop calibration is based on a steady-state test. The validation consists of reproducing experimental steadystate tests with the engine model. The results in Figure 18 show that the LP EGR valve and the exhaust throttle positions from the simulation are very similar to experimental ones, with the same levels for BGR and intake manifold pressure. This steady-state validation has to be completed by the assessment of the transient behaviour of the model.

\subsubsection{LP EGR Circuit Transient Validation}

This transient validation is dedicated to a comparison between the experimental and simulation settling times for a LP EGR valve position step. The settling time analysis lies in the temporal evolution of the intake manifold AFR. During this test, engine speed, torque, and LP and exhaust throttle position set points are fixed. The other set points are calculated by the ECU. When a steady state has been reached, the operator imposes a position step for the LP EGR valve. This test is performed for several engine speeds and torques. In the simulation, VGT, LP valve and exhaust throttle positions are set so as to observe the same air and EGR mass flow rates as on the bench.

Two characteristic times are evaluated (Fig. 19):

- Tau15: Delay between the step start and the time when the intake manifold AFR reaches $15 \%$ of its final value (AFR15), 

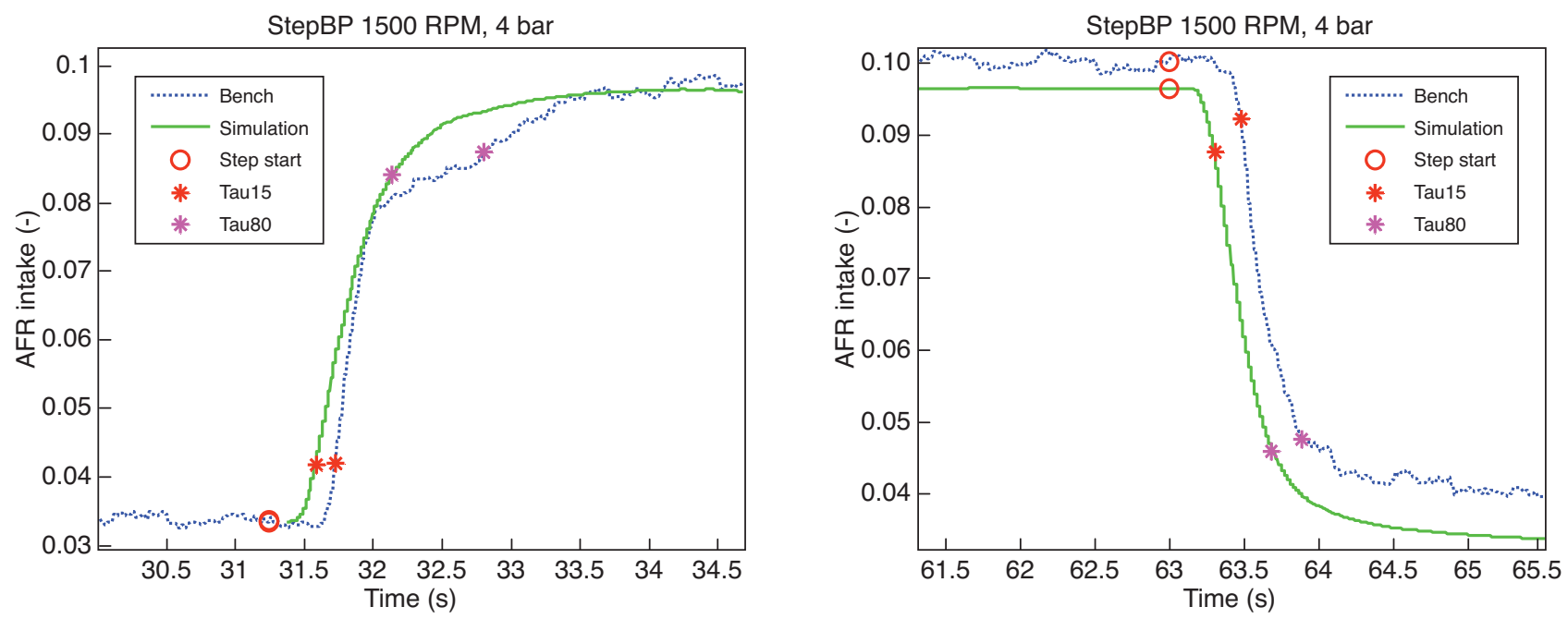

Figure 19

Time-based evolution of intake manifold AFR for an ascending and a descending LP EGR valve step.
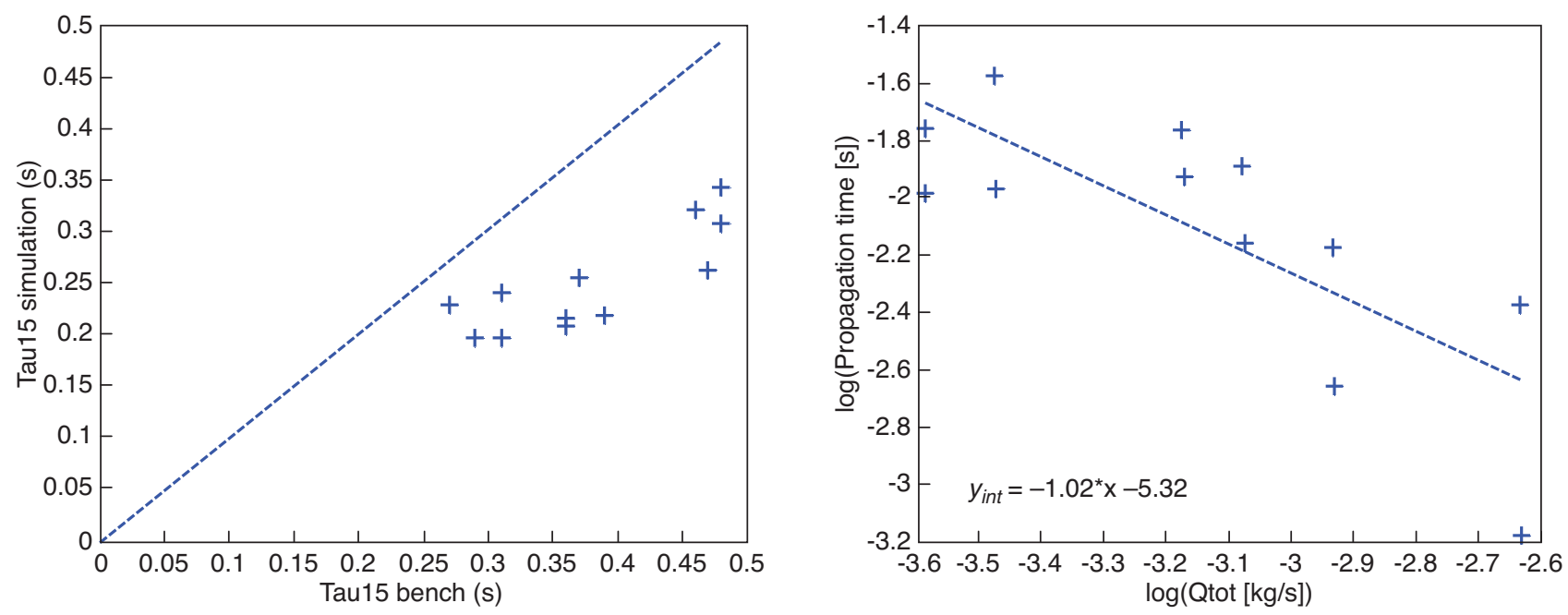

Figure 20

Comparison between simulation and bench Tau15 (left), and correlation between propagation time and total mass flow rate (right).

- Tau80: Delay between the step start and the time when the intake manifold AFR reaches $80 \%$ of its final value (AFR80).

Comparison between experimental and simulated Tau15 shows that the settling time of the simulator is shorter (Fig. 20). This can be explained by the fact that a OD simulator is not adapted to the modelling of propagation times. Indeed, such a time corresponds to the propagation of a singularity, which is not possible in OD modelling as all the values are averaged. Assuming that:

SettlingTime $=$ PropagationTime + DynamicTime it is normal to have shorter settling times in the simulation as the propagation time is null. Considering this fundamental limitation of OD models, it is more relevant to compare simulation and experimental dynamic times rather than settling times. The difficulty lies in the ability to distinguish quite accurately propagation times and dynamic times.

The experimental settling time at $15 \%$ (Tau15) is the sum of a propagation time and a dynamic time, whereas the simulated Tau15 in assumed to be purely dynamic. So, the difference between simulated and experimental Tau15 should give a good estimation of the propagation time (TauProp):

$$
\text { TauProp }=\text { Tau15_expe }- \text { Tau15_simu }
$$




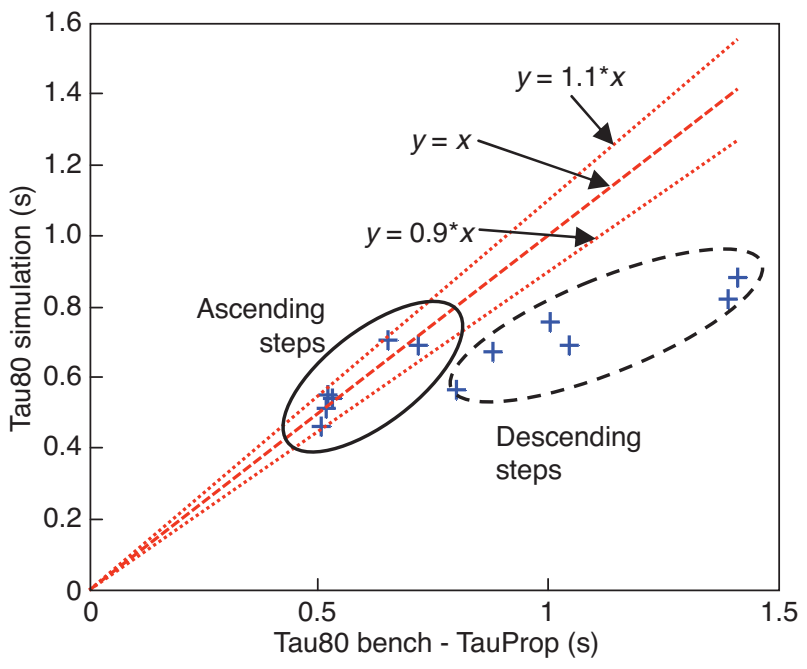

Figure 21

Comparison of simulation and bench dynamic times.

Moreover, the propagation time can be evaluated by the formula:

$$
\operatorname{TauProp}(\mathrm{s})=\frac{V\left(\mathrm{~m}^{3}\right) \cdot \rho\left(\mathrm{kg} / \mathrm{m}^{3}\right)}{Q(\mathrm{~kg} / \mathrm{s})}
$$

where $V$ is the volume of the air path between the LP EGR valve and intake manifold.

So, we should have: $\log ($ TauProp $)=-1 \cdot \log (Q)+\log (V \cdot \rho)$. This is verified in Figure 20. Indeed, the linear interpolation gives a slope close to -1 as expected. Besides, we have $\log (V . \rho)=-5.32$. Assuming that $P=1.2$ bar and $T=320 \mathrm{~K}$, this leads to $V=4 L$, which is close to the real volume of an engine's admission line. This leads to the conclusion that the difference between the simulated and experimental Tau15 is a good estimation of the propagation time. This allows an accurate computation of experimental dynamic time at $80 \%$, defined as: TimeDyn $=$ Tau $80-$ TimeProp .

Figure 21 shows that simulated dynamic times are very similar to experimental ones, mainly for descending steps. Ascending steps dynamic times are less accurate with the simulator because there is a break in the experimental slope that the simulator does not reproduce (Fig. 19).

Even if the propagation time is not reproduced by the model, simulation and experimental dynamic times are quite similar, without having to change the calibration of the capacitive elements. Nevertheless, a better understanding of the phenomena causing the slope break in ascending steps is necessary, as well as the analysis for other types of steps, such as exhaust throttle steps or injected fuel mass steps.

\subsection{Simulation-Based HP/LP EGR System for Engine Design and Control Development}

The proposed simulator can be used for many purposes regarding engine air path architecture study or control development. For the Diesel air system architecture sizing several key points can be investigated:

- the turbocharger matching, in particular in the HP EGR configuration where the gas flow through the turbine can be strongly decreased by the use of a high HP EGR flow rate,

- the cooling system is also a key point with a dual loop system; the engine simulator can help to determine whether or not a HP EGR cooler is required (depending on the balancing between the EGR LP and EGR HP utilisation region),

- Influence of the EGR circuit volumes on EGR settling times,

- EGR valve technology impact on the system performance (three-way valve, LP valve with an exhaust throttle, LP valve combined with an intake throttle).

For the control the simulation platform can be applied to test and validate several control cases:

- Case 1: the HP and LP EGR flow estimators,

- Case 2: the HP control (the simulation results are presented in Sect.2),

- Case 3: the LP control (see Fig. 22),

- Case 4: the supervisor that manages the HP and LP flow control system,

- Case 5: turbocharger control strategies during various engine operating conditions (in HP EGR mode, in LP EGR mode, during HP/LP EGR switching).

Two applications of the simulation platform are reported in this section regarding case 3 and case 5. The simulation results clearly show the relevance of the proposed approach in terms of engine behaviour reproduction.

\section{Example of case 3: Torque Trajectory at Constant Engine} Speed in LP EGR Configuration

This validation principle lies in reproducing an experimental torque trajectory with the simulator. All the actuators' set points come from the control strategy. Figure 22 shows a good agreement between the model and the test bench results. Concerning steady-state levels, it appears that the model reproduces quite accurately air and EGR mass flow rates as well as LP valve and exhaust throttle positions. Concerning the dynamic behaviour, even if the model tends to filter the experimental overshoots, it is nevertheless quite close to the real engine behaviour.

\section{Example of Case 5: Impact of the HP\LP Loop Switch}

This test aims to assess the behaviour of the simulator when submitted to a switching between the HP system and the LP system. The purpose of this test is to understand the transient 

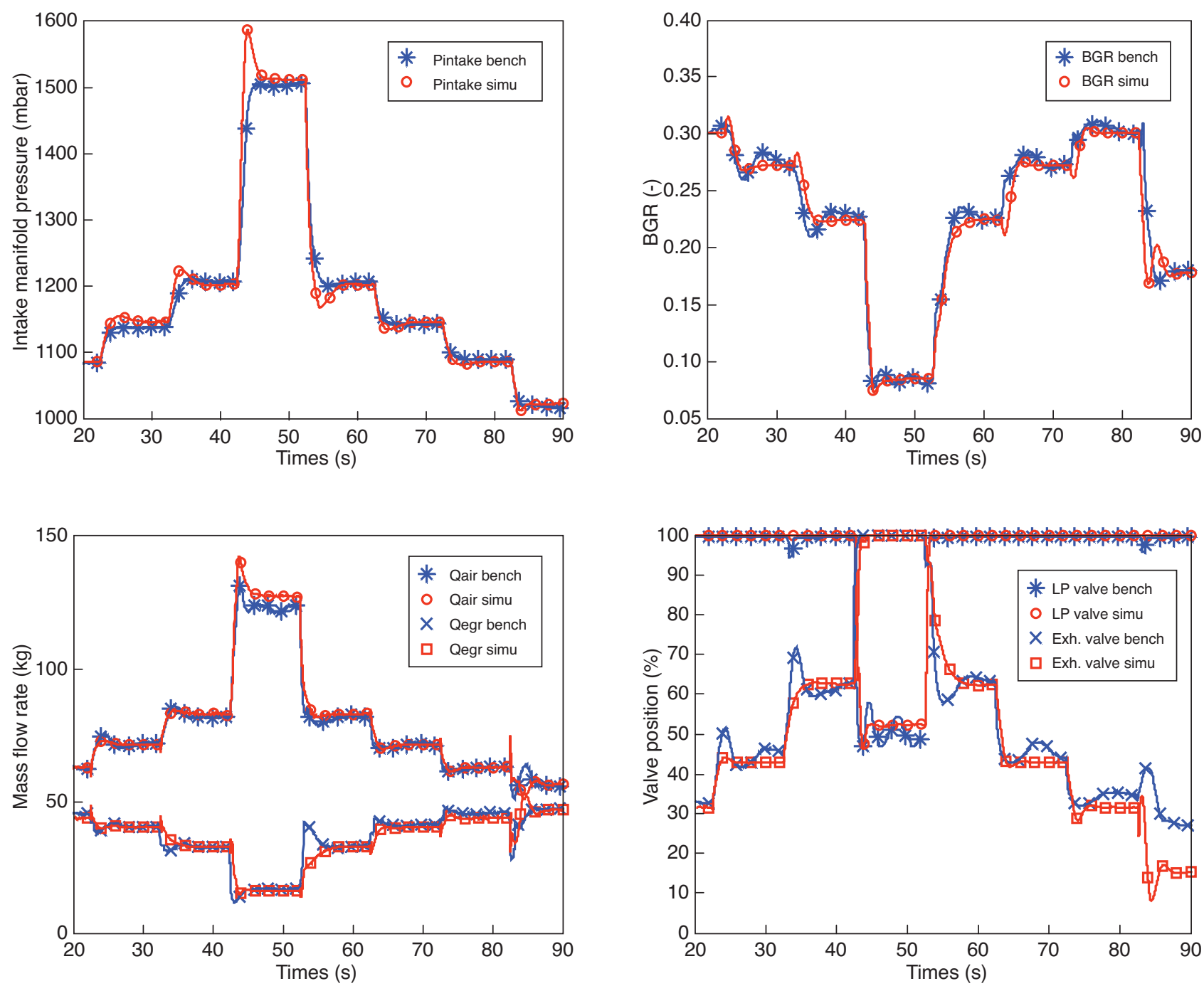

Figure 22

Comparison between simulation and bench results for a torque trajectory at $1500 \mathrm{rpm}$.

interaction between the two EGR loops and the turbocharger when the switching is performed on a steady engine condition. On the bench, engine speed, torque and VGT position are set by the operator and remain constant during the whole test. The other set points are calculated by the ECU. When a steady state has been reached, the operator forces the control to switch from HP to LP EGR loops (at $t=12 \mathrm{~s}$ and at $t=$ $27 \mathrm{~s}$ in Fig. 23). The same test configuration is reproduced with the engine model. The VGT position is set to obtain the same pressure downstream of the compressor as on the test bench. The following figures (Fig. 23) present the results of an experiment and simulation performed at constant engine speed $(1500 \mathrm{rpm})$ at 4 bar of IMEP. Valve positions and mass flow rate results are quite close to experimental ones.
Two cases can be considered:

- Case A: LP to HP switching. At time $t=12 \mathrm{~s}$, the impact of EGR circuit switching is well represented on the intake manifold pressure. The exhaust flow across the turbine is reduced by the use of HP EGR; then, the energy transferred to the compressor is less. As a result, if the VGT command is not corrected, the intake manifold pressure decreases,

- Case B: HP to LP EGR switching. At time $t=27 \mathrm{~s}$, the engine recovers the same intake manifold pressure as before the LP to HP switch. However, there is a transient to reach the LP EGR flow steady condition. During this transient, the BGR displays an undershoot that corresponds to the EGR LP circuit filling delay: the HP EGR 


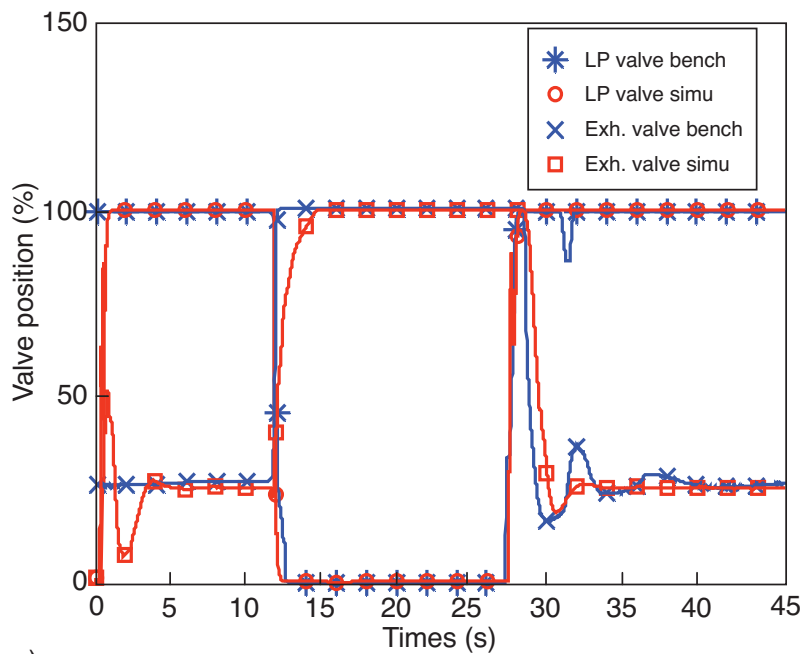

a)

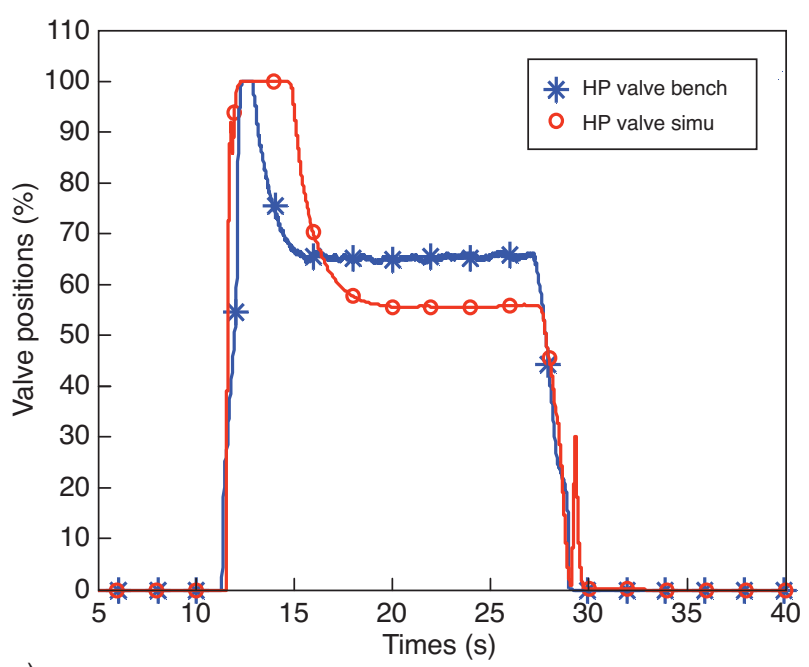

c)

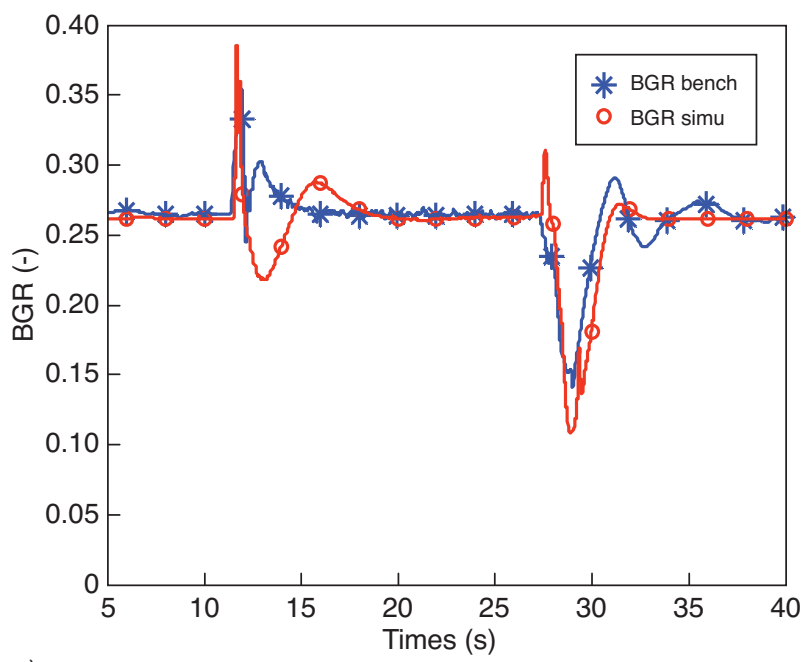

e)

Figure 23a, b, c, d, e

Comparison between simulation and bench results for a LP\HP EGR loop switch.

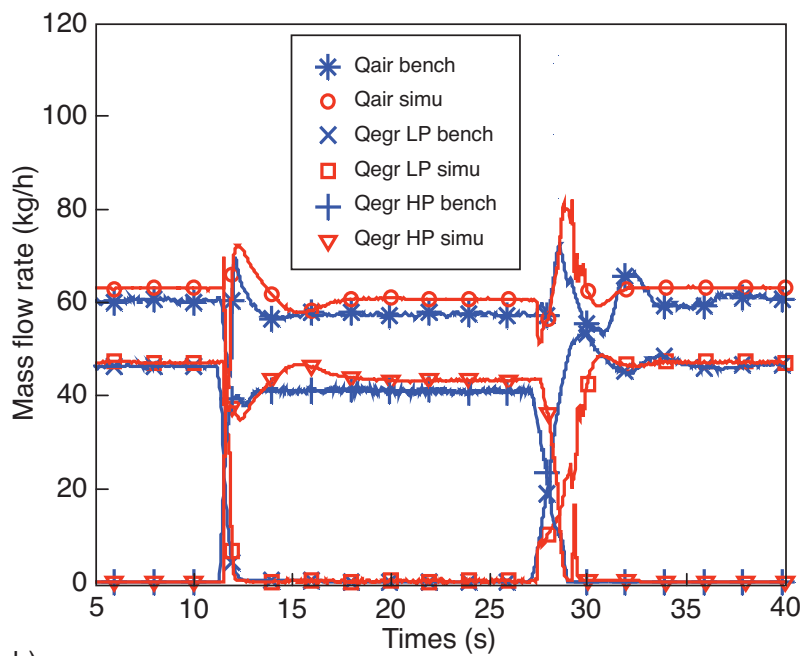

b)

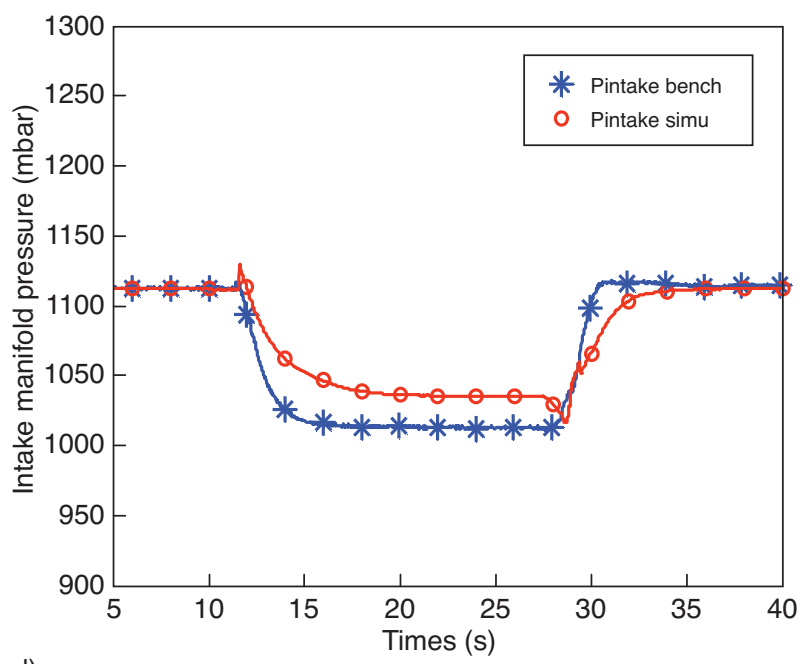

d)

circuit is emptied almost instantaneously while the LP EGR system has a longer settling time. The oscillating behaviour observed experimentally is not reproduced in the simulator because the exhaust throttle dynamic model is not included. This explains the small differences between experimental and simulated data.

\subsection{Introducing Variable Valve Actuation (VVA)}

Another interesting approach to reintroduce burnt gas into the cylinder consists of using variable valve actuation [13]. The engine simulator was modified, dismantling the HP EGR loop and adding a VVA system to the existing LP EGR loop. This VVA system is able to manage a secondary lift of the 


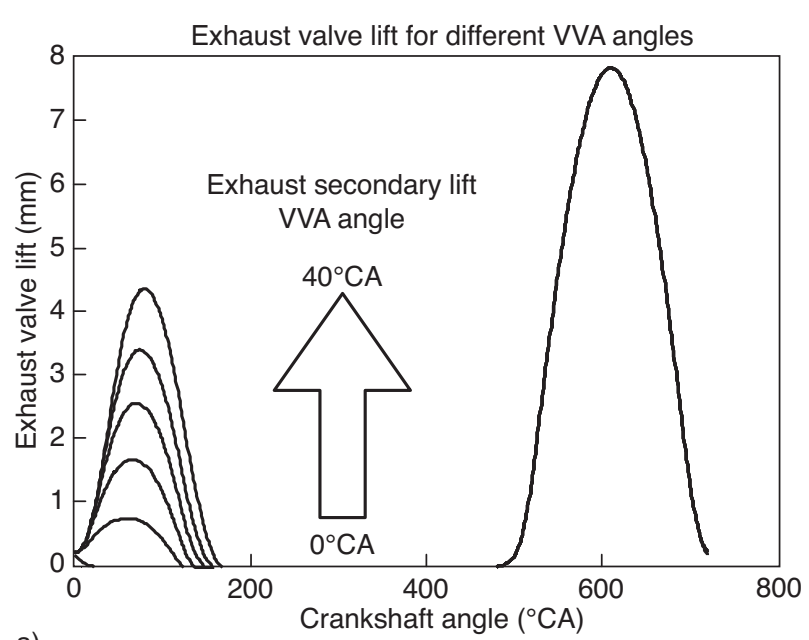

a)

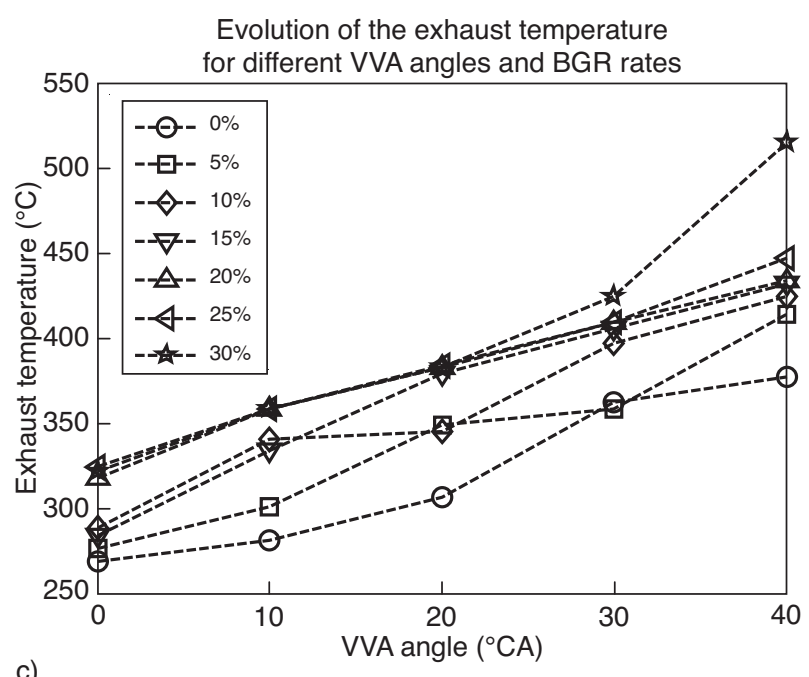

c)

Figure 24

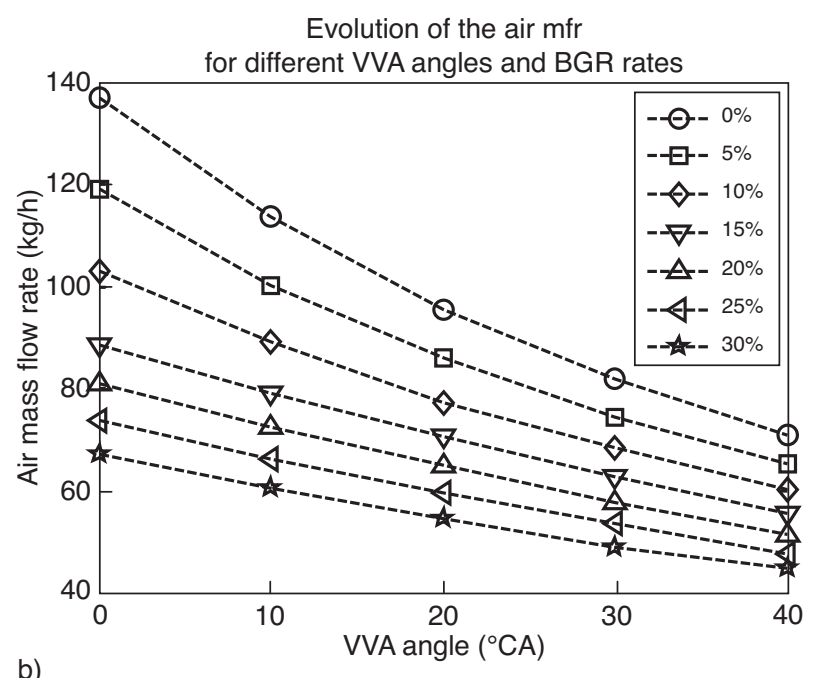

b)

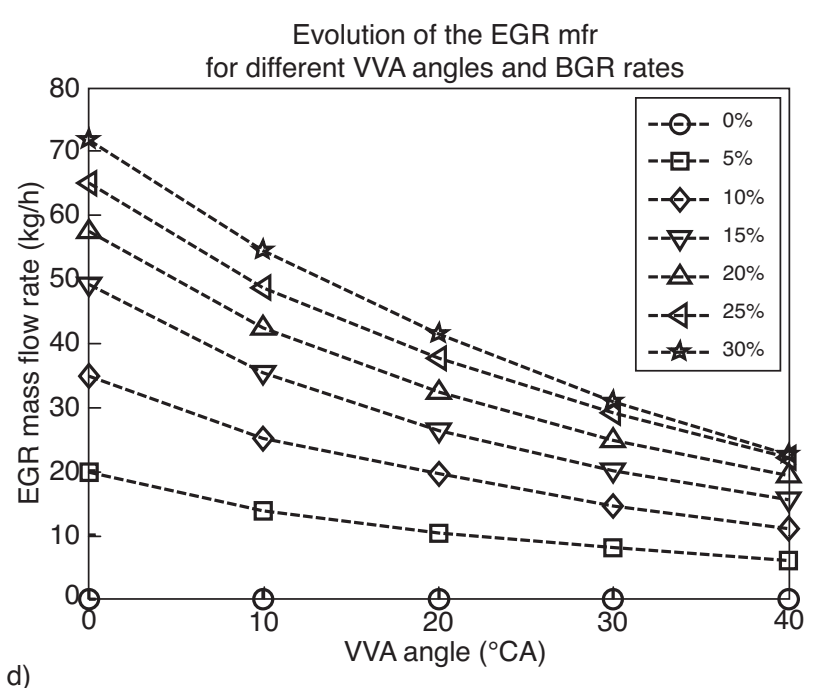

Evolution of engine simulator behaviour for different VVA angles and BGR rates: exhaust valve lift variation (top left), air mass flow rate (top right), exhaust temperature (bottom left) and EGR mass flow rate (bottom right).

exhaust valve to readmit burnt gas. This new actuator allows controlling the in-cylinder conditions, especially the re-aspirated burnt gas amount. Firstly, the simulation of the complex system helps to understand its behaviour. Then, to control this type of air path, it is very important to estimate the in-cylinder burned gas mass and the exhaust temperature. The simulation can be very helpful in this context to apprehend this issue because it permits access to in-cylinder information. Moreover, the simulation allows implementing the control strategies before the engine is available at the bench.

The first step before using the simulator as a development support is to be sure its behaviour has a sufficient representative capability for the target control issues. In the current case, particular attention is accorded to the air mass flow rate, the EGR mass flow rate and the exhaust temperature trends for different exhaust secondary lifts.

Figure 24 presents the exhaust valve lift with different secondary lifts. When the VVA angle is equal to 0 , there is no secondary lift. The VVA angle equal to 40 is the highest secondary lift. This figure also presents the evolution of the air mass flow rate, the EGR mass flow rate and the exhaust temperature for different exhaust secondary lifts and BGR values. Each symbol represents a fixed BGR.

These results show that the behaviour of the simulator is quite good according to what can be expected from such operating condition variations. The more significant the 
exhaust secondary lift, the more the air mass flow rate and the EGR mass flow rate decrease, and the more the exhaust temperature rises.

These figures show the advantage of an exhaust secondary lift. For the same BGR in the intake manifold, the exhaust temperature is more significant with a high secondary lift which allows the best oxidation of the UHC and the $\mathrm{CO}$ in the cylinder and shorter light-off duration.

\section{TWO-STAGE TURBOCHARGER: TO ENSURE AIR BOOST HIGH PERFORMANCES}

This section describes how an engine simulator was used for one year to set up a Two-Stage (TS) turbocharger air path control without any experimental support from the target engine.

\section{1 Context}

Due to severe emissions constraints, one major aspect of new Diesel engines is their capacity to provide fresh air to the system even with high EGR rates. To that end, the two-stage turbocharger has been found of great interest. Indeed, it enables the extension of the engine operating range with high EGR levels but also increases the power production, by allowing a higher quantity of air in the cylinder at high engine speed.

In this section, the engine considered is a 2,0L 4-cylinder Diesel engine fitted with high-pressure EGR. It was adapted from a production engine, in order to reach higher torque

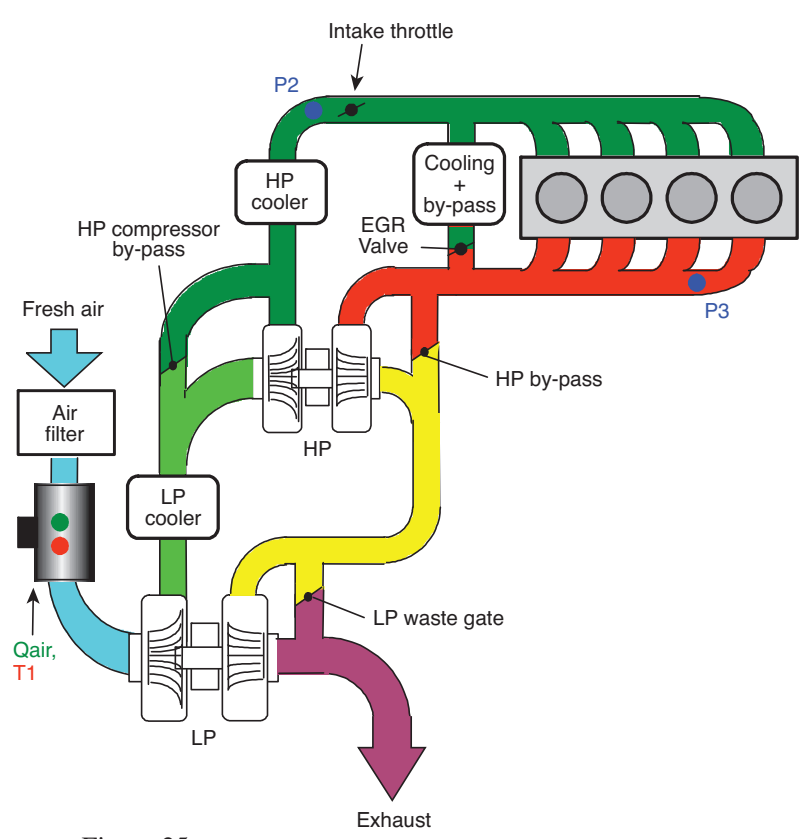

Figure 25

Two-stage turbocharger Diesel engine setup.

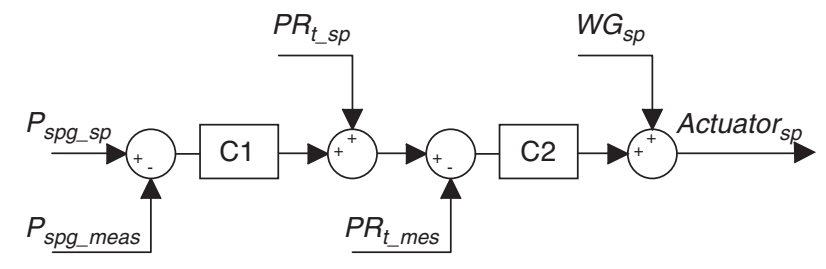

Figure 26

Single-stage turbocharger control structure.

levels thanks to an excess of air provided by the supercharging system. Therefore, the combustion chamber was modified, with a decreased compression ratio. The air intake system was completely redesigned. Figure 25 describes this engine setup.

\subsection{Specific Two-Stage Turbocharger Control Issues}

The main objective of the engine control strategies was to produce a required mechanical torque on the engine shaft. This torque is released during the combustion of the mixture of air and fuel in the cylinder. In a Diesel engine, the combustion efficiency and the resulting pollutant emissions are linked with the mass and composition of gas aspirated by the cylinder. The engine gas mass flow depends on the intake manifold air density, while the intake gas composition depends on the balance between EGR flow and fresh air flow. Conventionally, the air path management structure considers two problems which are dealt with independently: the control of the fresh air mass flow via the actuation of the EGR valve, and the control of the intake manifold pressure via the turbocharger. In a single-stage turbocharger system, the control strategy acts on the turbine in order to follow a compressor downstream pressure set point (cf. Sect. 2). Additionally, two constraints have to be respected for safety reasons: the turbocharger speed and the exhaust manifold pressure have to be maintained below maximum values. The control law must also be robust with respect to changes in environmental conditions: the thermodynamic conditions at the boundaries of the system will affect its behaviour.

Figure 26 represents the turbocharger control strategy that is used for a single-stage turbocharger. This controller is composed of two cascaded controllers. The first one (C1) computes a turbine pressure ratio set point $P R_{t_{-} s p}$ in order to control the compressor outlet pressure measurement $P_{\text {spg_meas }}$ to its set point $P_{s p g_{s} s p}$. The second controller (C2) actuates the waste gate $W G_{s p}$ in order to track this set point. Feed-forward terms depending on the engine operating conditions are added to both controllers. A similar structure is described, for example, in [14]. 
The goal of this project was to adapt this structure to the specific issues of double-stage turbocharging. A major constraint was to do so without adding any new sensor, particularly between the two compressors or the two turbines.

The main control strategy goals for such a system were:

- the closed-loop control of the intake manifold pressure,

- the steady-state feed-forward, taking into account variation in environmental conditions,
- respect for the system's safety limits, the most important being the turbocharger maximum speed and the maximum exhaust pressure,

- failure detection and adaptation of the safety strategies.

\subsection{Modelling Adaptation}

In the particular context of the project, the main features required for the engine simulator were:

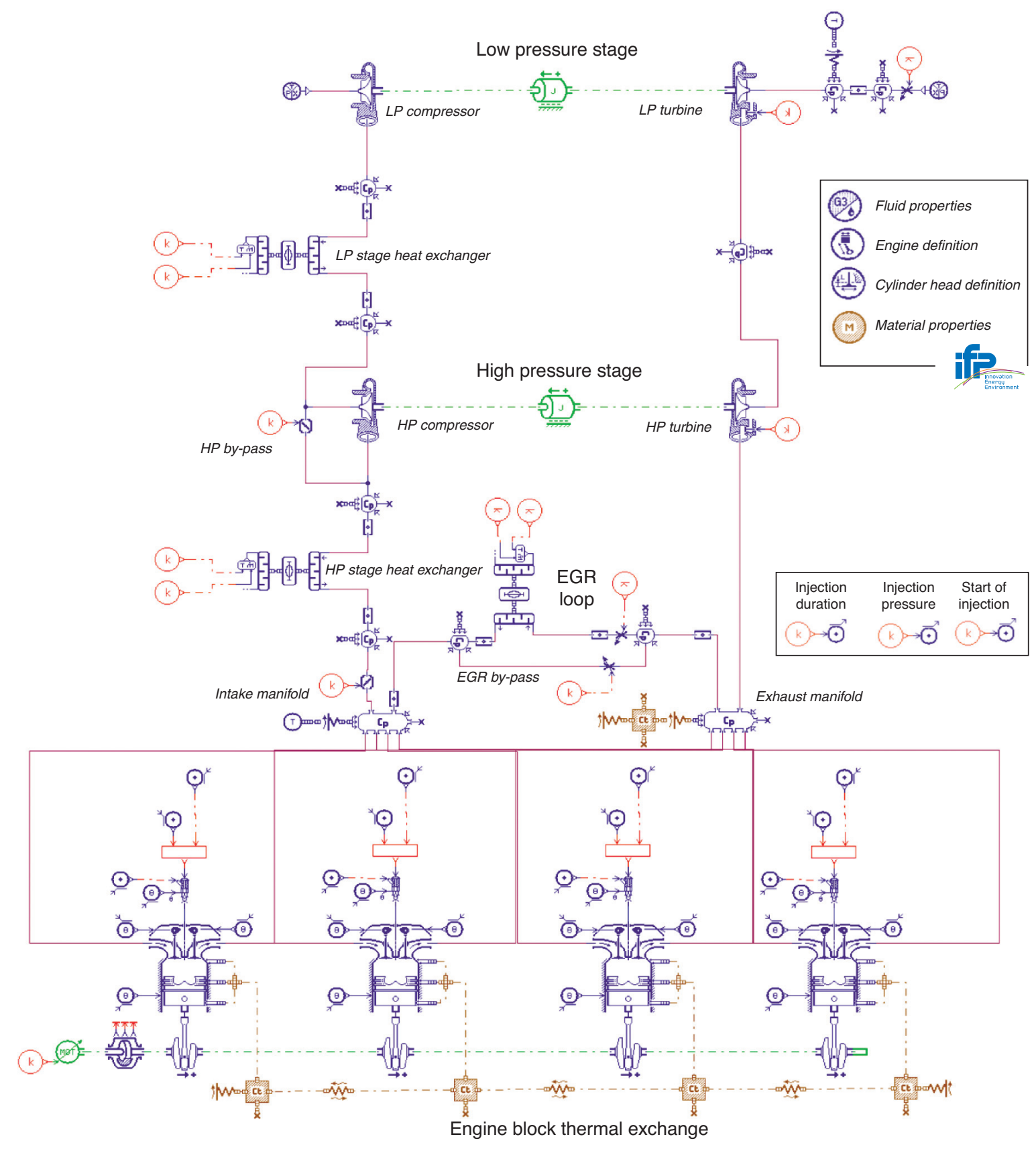

Figure 27

AMESim diagram of the two-stage turbocharger Diesel engine simulator. 

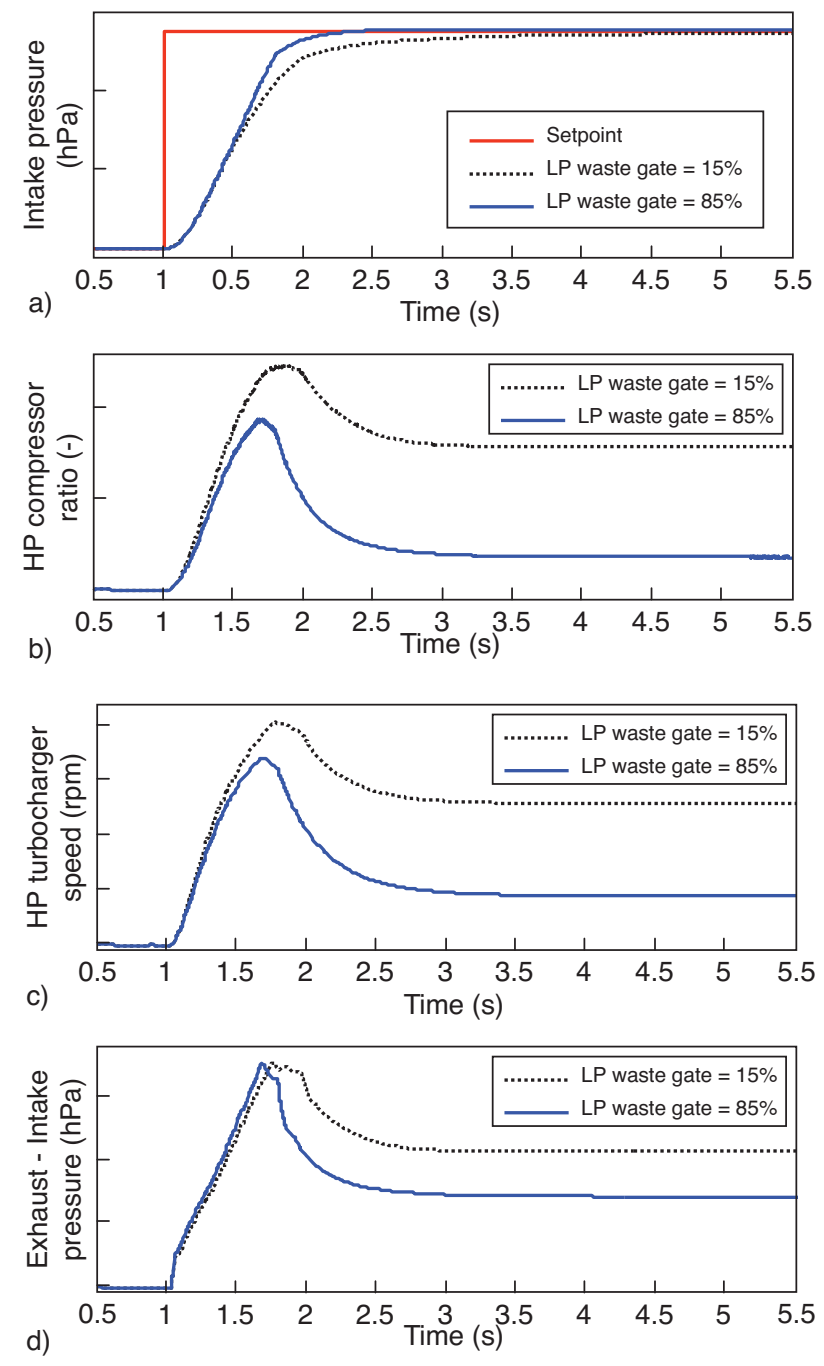

Figure 28

Effect of the variation in the LP waste gate opening on the intake pressure a), the HP compressor ratio b), the HP turbocharger speed c), and the difference in pressure between the exhaust and the intake d).

- the balance between the pressure ratio of the two turbochargers at the intake (compression) and the exhaust (expansion) in steady state,

- the dynamic time constant of each turbocharger during transients,

- the effect of environmental conditions on the system, correct behaviour in the EGR zone.

In order to match the simulator accuracy requirements, a dedicated methodology was set up according to the simulation representative ability expected for the control design and to the available test bed results from other engines. The control development is focused on command, strategy and diagnosis for the Two-Stage turbocharging (TS) air circuit. This part of the engine simulator is therefore the most important. Turbocharger response time, supercharging stage balance and air path dynamics are the main phenomena that need to be well reproduced. As a consequence, the air path description has to be accurate enough. Turbocharger maps (compressor, turbine), turbocharger inertias, main pipes and volumes and the air path layout diagram are thus required. Fortunately, two-stage turbocharged Diesel engine preliminary developments have already been achieved on a smaller engine, and full load operating points and transients were available from this prototype vehicle. The specific methodology used to develop this engine simulator without target engine experimental results is presented in detail in [15]. The engine simulator diagram is presented in Figure 27.

\subsection{Simulation-Based Two-Stage Turbocharger Control Study}

Since the simulation was the only control development support for one year, the engine simulator was fully used as a virtual bench. The main objective of the first tests performed on the engine simulator was to study the impact of the LP waste gate position on the global system, and in particular on the HP turbocharger dynamics.

The results presented in Figure 28 show load transient tests with two different positions of the LP waste gate $(15 \%$ and $85 \%$ of closing). The supercharging pressure is controlled by an action on the HP turbine by-pass. It can be noticed that a single-stage controller can be applied to the HP stage, the LP stage being considered as a simple perturbation.

The first observation that can be made from these figures is that the HP turbocharger speed reaches high values in transient conditions and stabilises at lower values. The low time response of the LP turbocharger is compensated for by the faster HP stage. Because of this phenomenon, an over-speed problem can arise if the HP system works close to its speed limits. An important fact is that the sensors available on the system do not give any information about the HP turbocharger speed. The HP compressor outlet pressure sensor provides a value that is the consequence of both compressions. They cannot be isolated.

Another important observation is that a closed position of the LP waste gate is always beneficial to the system. In transient operations, it makes the global system dynamics faster (intake pressure and air flow rate), whereas in steady state it decreases the difference between the exhaust pressure and the intake pressure, reducing engine pumping losses. The HP stage dynamics are not modified by the LP waste gate closing. The pressure ratio and the turbocharger speed dynamics are independent of the conditions at its boundaries. 


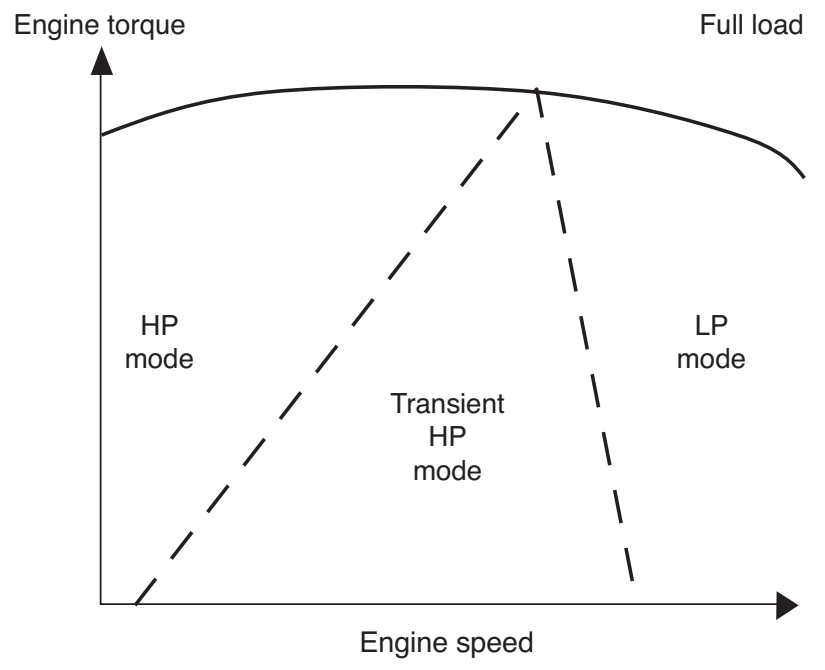

Figure 29

The operating modes of the two-stage turbocharger.

In summary, this analysis leads to two important conclusions:

- when the HP turbocharger is used, the LP waste gate has to be closed,

- there is a risk of HP over-speed in transient operations.

Thanks to these first tests, the system operating modes could be defined as plotted in Figure 29, and led to the development of the control strategies, notably the transitions between the different operating modes (please refer to [16] for more details).

These strategies have been developed following the approach which consists of standard tests that were performed on the simulator, providing references for a comparison between different strategies and calibrations. The different tests used were:

- steady-state tests, for the determination of open-loop feedforward terms,

- transient tests, for an evaluation of the strategy performances in terms of response time, overshoot and stability,

- failure simulation, for the validation of diagnosis strategy: in the simulator, it is possible to represent leakages at various locations along the intake and exhaust circuits and to verify that the strategies can deal with those problems (detection and adaptation),

- environmental conditions variations: it is possible to simulate a change in atmospheric pressure and temperature, or an increase in the after-treatment system back pressure (DPF loading, etc.), and to verify that the control strategies work well in those conditions (in steady state and in transient conditions),
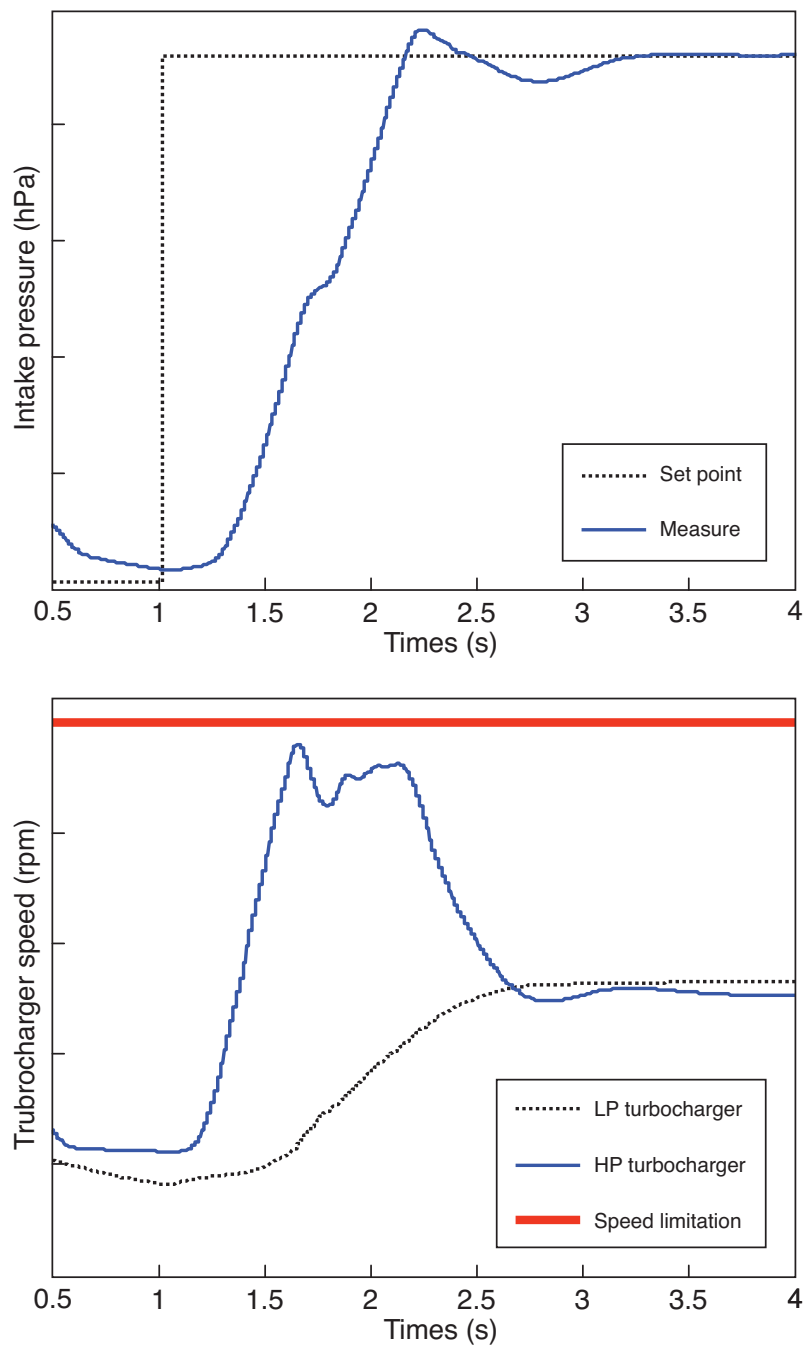

Figure 30

Co-simulation results for a load transient at $2000 \mathrm{rpm}$ : supercharging pressure (top) and turbocharger speeds (bottom).

- component dispersion simulation: an important requirement of the strategies is the robustness against production dispersions (sensors, actuators, components); the performances of the control algorithms were verified in transient conditions while accounting for these dispersions.

Even if some of those tests $(1,2)$ could have been performed on a real test bed, the use of simulation has provided a way of accelerating and facilitating the development process. However, in some cases, the tests would not have been possible on a real engine: it would either require damaging some components (3), or a very high number of tests (4, 5). As a matter of fact, the use of simulation tools for those tests is not only necessary, but also provides information that would not be available otherwise. 

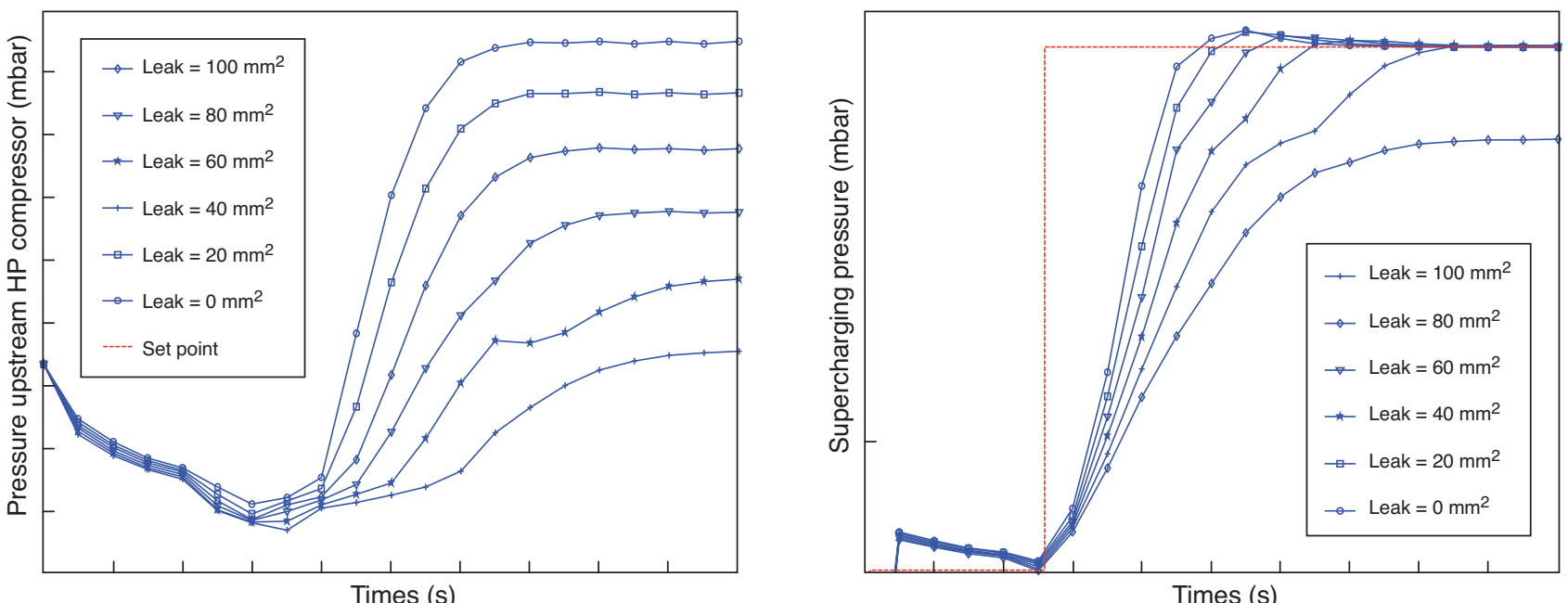

Figure 31

Co-simulation results for a transient load at $1500 \mathrm{rpm}$ with different leakages before the HP compressor: pressure upstream of the HP compressor inlet (left) and supercharging pressure (right).
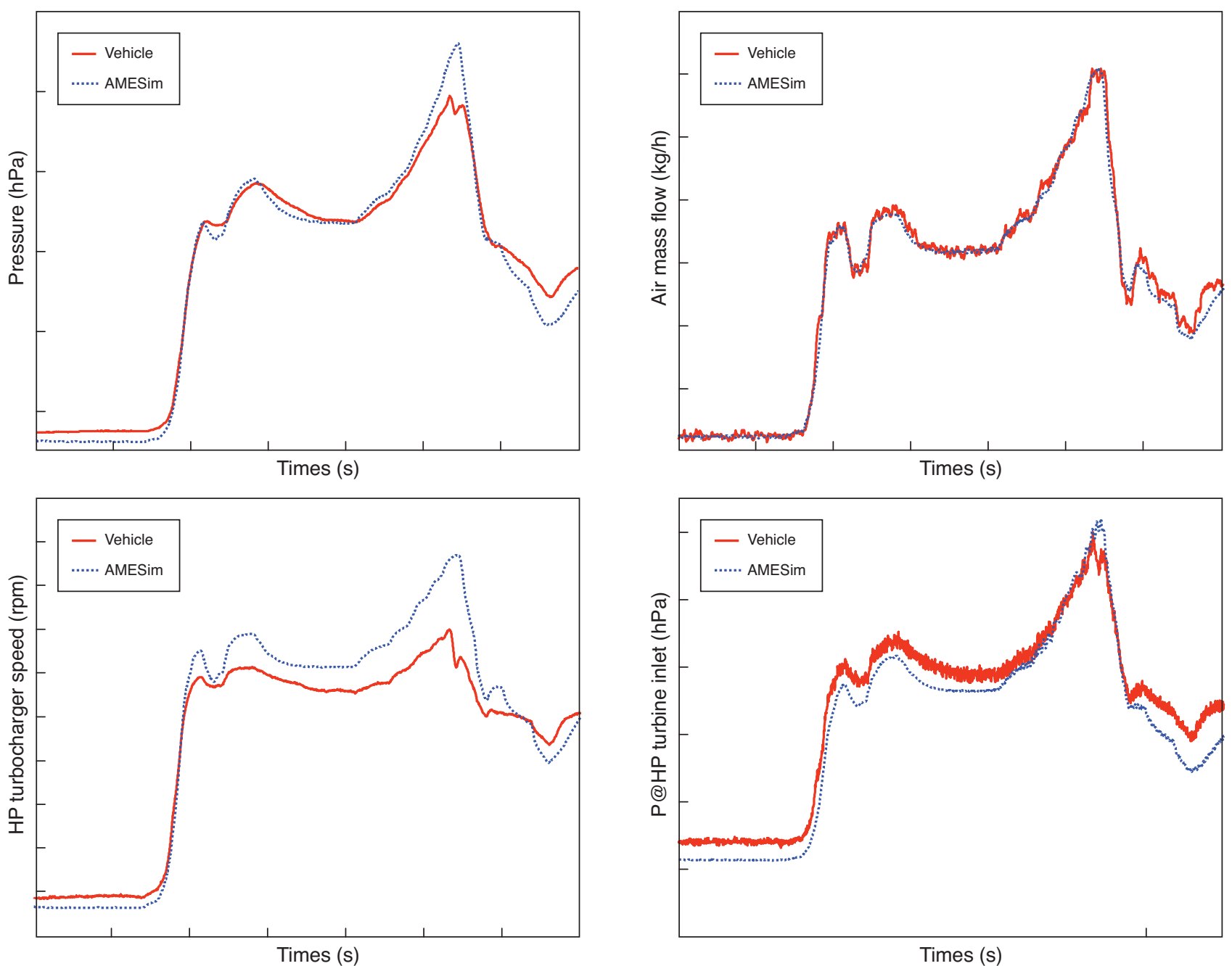

Figure 32

Comparison between vehicle results and simulation results for a transient extracted from a NEDC cycle: manifold pressure (top left), air mass flow (top right), HP turbocharger speed (bottom left) and exhaust pressure (bottom right). 
The following figures show some examples of the tests performed by simulation: Figure 30 shows intake pressure, and LP and HP turbocharger speed during a load transient at a constant engine speed $(2000 \mathrm{rpm})$. This transient shows that, thanks to a specific control strategy, the HP turbocharger speed remains under the safety limitation.

Figure 31 shows transient tests with different leakages simulated before the HP compressor. These tests show the small impact on the supercharging pressure of a leakage between the two compressors, and thus demonstrate the real interest in an estimator of the HP inlet pressure to prevent the HP turbocharger from any over-speed.

\subsection{Engine Simulator a Posteriori Validation}

Finally, the hard engine has been available for one year and some a posteriori comparisons were made at the end of the project with measurements made on the vehicle (Fig. 32). This figure shows the good agreement of the engine simulator with the real engine despite the fact the simulator had never been calibrated with target engine results for one year. These final comparisons between simulation and measurement during a NEDC cycle prove the reliability of the methodology set up for this study. A complete description of this two-stage turbocharger engine study based on simulation is available in [17].

\section{CONCLUSION}

This paper has presented the way simulation was used to develop the air path control in the different typical issues of modern Diesel engines. For each air path system, a specific engine simulator was set up with more or less experimental data according to the context. The goal was to have a relevant tool to develop the specific control issues related to each air path system. For each case, the use of the simulation has been illustrated with control design results obtained using the simulator as a virtual bench.

Finally, the paper has demonstrated how control strategies can be developed with a simulation-based approach, even when the hard engine is not available. In this context, several simulation advantages were highlighted:

- it helps the physical understanding of the phenomena to control,

- it allows anticipation of the availability of the experimental support,

- it offers the possibility of performing different types of tests, including some that cannot be run on the real engine,

- it helps to reduce development risks by anticipating a potential specific control strategy (for instance, the HP turbocharger over-speed during load transients in Sect. 4).
This paper shows how engine simulation is a relevant and efficient support from the earlier stages of the engine control development.

\section{ACKNOWLEDGMENTS}

The authors wish to thank RENAULT for its financial support for simulation-based control development projects. They also wish to acknowledge the RENAULT and IFP test bed teams who provided the experimental results and Alexandre Chasse, Thomas Leroy and Mathieu Bitauld for their valuable technical contributions to this paper.

\section{REFERENCES}

1 Albrecht A., Grondin O., Le Berr F., Le Solliec G. (2007) Towards a stronger simulation support for engine control design: a methodological point of view, Oil Gas Sci. Technol. 62, 437456, http://ogst.ifp.fr/.

2 Albrecht A., Grondin O., Moulin P., Corde G. (2008) HCCI Diesel engine control design using advanced simulation with real time capabilities, Oil Gas Sci. Technol. 63, 535-551.

3 Albrecht A., Chauvin J., Lafossas F.-A., Potteau S., Corde G. (2006) Development of highly premixed combustion Diesel engine model: from simulation to control design, SAE paper 2006-01-1072.

4 Youssef B., Moulin P., Grondin O. (2007) Model based control of turbochargers: Application to a Diesel HCCI Engine, in Proceedings of the IEEE International Conference on Control Applications.

5 Heywood J.B. (1988) Internal combustion engine fundamental, Mc Graw-Hill, New York.

6 Mailboom A., Tauzia X., Hétet J.-F. (2008) Experimental study of various effect of exhaust gas recirculation (EGR) on combustion and emissions of an automotive direct injection diesel engine, Energy 33, 22-34.

7 Walter B., Gatellier B. (2003) Near Zero NOx Emissions and High Fuel Efficiency Diesel Engine: the NADI Concept Using Dual Mode Combustion, Oil Gas Sci. Technol. 58, 101-114, http://ogst.ifp.fr/.

8 Chauvin J., Corde G., Petit N., Rouchon P. (2007) Motion planning for experimental airpath control of a Diesel homogeneous charge compression ignition engine, Control Engineering Practice 26, 129-137.

9 Amman M., Fekete N., Guzzella L., Glattfelder A. (2003) Model based control of a VGT and EGR in a trubochearged common rail diesel engine: Theory and passenger car implementation, SAE paper 2003-01-0357.

10 Vigild C., Tumelaire C.-F., Röttger D., Karvounis E., Calendini P.O. (2006) Toward generic model based engine control - the concept, in Proceedings of the E-COSM - Rencontres Scientifiques de l'IFP, pp.95-102.

11 Wang J. (2007) Air fraction estimation for multiple combustion mode diesel engines with dual-loop EGR systems, in Proceedings of the 46th IEEE Conference on Decision and Control, pp. 2862-2867.

12 Karnopp D.C., Margolis D.L., Rosenberg R.C. (1990) System dynamics: a unified approach, Second Edition, John Wiley \& Sons, New-York. 
13 Bression G., Soleri D., Savy S., Dehoux S., Azoulay D., Ben-Hadj Hamouda H., Doradoux L., Guerrassi N., Lawrence N. (2008) A Study of methods to lower HC and CO emissions in Diesel HCCI, SAE paper 2008-01-0034.

14 Däubler L., Bessai C., Predelli O. (2006) Tuning Strategies for online-adaptive PI Controllers, Oil Gas Sci. Technol. 62, 493500, http://ogst.ifp.fr/.

15 Gautier P., Albrecht A., Chasse A., Moulin P., Fontvieille L., Guinois A., Doléac L. (2008) A new simulation step towards virtual bench through the challenging case of two stage turbocharger diesel engine control design, SAE paper 2008-01-0355.
16 Chasse A., Moulin P., Gautier P., Albrecht A., Fontvieille F., Guinois A., Doléac L. (2008) Double Stage Turbocharger Control Strategies Development, SAE paper 2008-01-0988.

17 Gautier P., Albrecht A., Chasse A., Moulin Ph., Pagot A., Fontvieille L., Issartel D. (2009) A simulation study of the impact of LP EGR on a two stage turbocharged Diesel engine, Oil Gas Sci. Technol. (to be published).

Final manuscript received in July 2008 Published online in May 2009 or distributed for profit or commercial advantage and that copies bear this notice and the full citation on the first page. Copyrights for components of this work owned by others than IFP must be honored. Abstracting with credit is permitted. To copy otherwise, to republish, to post on servers, or to redistribute to lists, requires prior specific permission and/or a fee: Request permission from Documentation, Institut français du pétrole, fax. +33147527078 , or revueogst@ifp.fr. 